\title{
Analysis of the performance in the linear field of Equivalent-Frame Models for Regular and Irregular Masonry Walls
}

\author{
Rossella Siano $^{1^{* \dagger}}$, Vincenzo Sepe ${ }^{1}$, Guido Camata ${ }^{1}$, Enrico Spacone ${ }^{1}$, Pere Roca ${ }^{2}$, \\ Luca Pelà ${ }^{2}$ \\ ${ }^{1}$ Department of Engineering and Geology, University “G. D’Annunzio” of Chieti-Pescara, \\ viale Pindaro 42, I-65127 Pescara, Italy \\ ${ }^{2}$ Department of Civil and Environmental Engineering, Universitat Politècnica de Catalunya (UPC-BarcelonaTech) \\ Jordi Girona 1-3, Barcelona, Spain
}

\begin{abstract}
The Equivalent-Frame Method (EFM), a simplified procedure for structural modelling of masonry constructions, is having a great success for the good balance that it allows between the accuracy of the geometrical description and the simplicity of the mechanical calibration.

Despite the widespread use of EFM in scientific and professional field, some uncertainties affect its application to the specific problem of the existing unreinforced masonry (URM) buildings. For these structures, in fact, irregular geometries, the presence of deformable diaphragms and the interaction with other structures in aggregate configurations represent hard-to-model features that limit the accuracy of EFM.

The paper presents a comparative study in the linear field between EFM and the more accurate Finite Element Method (FEM), assumed as reference. The comparative analysis involves a wide set of geometrical schemes, characterized by both regular and irregular configurations, and it is aimed at providing a measure of the EFM modelling accuracy as a function of the geometry of the wall. Nondimensional parameters allow exploring the limits of applicability of EFM for both regular and irregular walls.

Based on the parametric analyses, some recommendations are given for improving the effectiveness of the method and preserving the simplicity of application that makes EFM models so popular and widely used.
\end{abstract}

KEYWORDS: Masonry structures; URM walls; Equivalent-Frame Models (EFM); Irregularity; Seismic vulnerability.

\footnotetext{
${ }^{*}$ Correspondence to: Rossella Siano, Department of Engineering and Geology, University of Chieti Pescara viale Pindaro 42, I-65129 Pescara - Italy

† E-mail: rossella.siano@unich.it
} 


\section{INTRODUCTION}

Unreinforced masonry (URM) buildings represent one of the oldest structural systems still in widespread use all around the world for hosting human activities. A large part of the built heritage in Europe and Mediterranean Area, but also in Asia and South America, consists of URM constructions. This means that a relevant portion of humanity still leaves or works in masonry buildings. At the same time, URM constructions are usually characterized by a high exposure to seismic hazard. Masonry constructions are in fact widespread in countries characterized by moderate to highseismicity. The use of poor materials and constructive technologies, the frequent lack of an engineering design process, in addition to the ontological heterogeneity, anisotropy and low tensile strength of these constructive systems, induce frequently a high seismic vulnerability to URM buildings.

All these peculiarities have motivated, in the last decades, an increasing interest of researchers towards the development of methods for the assessment and analysis of masonry structures [1]. Due to the complexity of the problem, the researchers addressed their work to the simplification and the rationalization of the structural analysis process to obtain modelling tools with general and reliable application to any masonry construction. In this context, a successful approach has been the Equivalent-Frame Method (EFM) [2-4]. EFM is a simplified method aimed at the simulation of masonry in-plane walls' behaviour by means of their identification with a frame. Given this assumption, the interpretation of masonry walls' behaviour can be faced by deriving modelling procedures from the study of reinforced concrete (RC) and steel framed structures, for which a betterestablished theoretical approach is available thanks to more engineered technologies and a larger period of dedicated studies.

The application of EFM to masonry structures is reasonably effective in the case of new buildings. In the case of new constructions, the regularity of the geometrical configurations and the tendency to a box-like behaviour match the theoretical assumptions of the Equivalent-Frame discretization. Some uncertainties affect instead the effectiveness of EFM in case of URM existing buildings both in the interpretation of the non-linear behaviour of the single panels and in the description of the global behaviour of the wall. Regarding the behaviour of masonry panels, axial loading rates, piers' geometry and boundary conditions can deeply affect their in-plane resisting mechanisms, resulting in failure mechanisms very far from those of the classical beam-elements. Also, the global performance of existing masonry constructions is usually affected by many hard-to-model features, such as low quality of masonry, irregular geometries, deformable diaphragms, low effectiveness of diaphragmto-wall and wall-to-wall connections and interactions with other structures in aggregate configurations.

Up to now, a great attention has been focused on the validation of EFM accuracy in predicting the actual behaviour of existing masonry buildings. The validation of EFM accuracy involved numerous experimental tests [5-9], simulations of existing damaged structures [10] or comparison with more detailed finite element modelling procedures [9-10]. In particular, the experimental campaigns carried out on full-scale building prototypes were very useful in providing information about the EFM modelling performance. Among these experimental tests, very successful was the quasi-static cyclic tests carried out at the University of Pavia [11] on a two-story building prototype. The great amount of information available on the test setting and the possibility to model separately the loadbearing walls made this test a crucial reference to verify the modelling accuracy of EFM. The numerical results provided by the EFM simulations [5-7] have demonstrated a good agreement with the experimental results, both for seismic capacity and failure mechanisms. However, the selected prototype is hardly representative of all the possible geometrical configurations recurrent in existing buildings. The structure tested in Pavia included in fact only regular walls whose geometrical configurations showed a remarkable compatibility with the classical frame representation. 
The interest towards the EFM modelling performance has led to the proposal of numerous comparative analyses between different EFM formulations [12-14]. These comparative studies have involved the most common EFM formulations, whose modelling accuracy has been tested on simple and regular structural systems. The comparison between EFM procedures, based on different mechanical models, has allowed to identify the critical aspects that mainly affect the modelling results. The aforementioned contributions demonstrate the great interest of the scientific world in the EFM. At the same time, the great variability of the results provided by different EFM formulations and the strong influence of the geometrical configurations confirm that large uncertainties are still affecting the performance of these methods.

Limitations have characterized the validations so far performed for EFM. The technical and economic difficulties have limited the possibility to carry out a comprehensive experimental study. Only a reduced number of experimental tests on full-scale building prototypes are actually available. Besides, all the experimental and numerical validations have regarded standard buildings, which are buildings composed of masonry walls with a regular distribution of openings and well interconnected to each other. No detailed validations are currently available about the suitability of EFM to simulate the structural behaviour of buildings with irregular walls. This justifies the effort to provide a systematic numerical validation for EFM as that described here. The topic was recently investigated in Siano [15] and Siano et al. [16]. These works introduced the concept of geometrical affinity, or frame-like performance, between an URM wall and its virtual frame configuration, as a key point to evaluate the accuracy of EFM results.

Following the same approach, the present paper assesses possible limits and potentiality of EFM in simulating the in-plane structural behaviour of URM walls in the linear field. The study of EFM performance in the linear field represents a necessary preliminary step of a wider study aimed at estimating the limits of applicability of EFM to URM walls both in linear and non-linear fields. The study involves both the cases of regular and irregular walls. The research provides a measure of the EFM accuracy as a function of the degree of affinity between masonry walls and frame configurations. With this aim, the non-dimensional parameters, defined in Siano [15], provide a measure of EFM applicability for regular configurations as a function of their geometrical properties. With an analogous approach, the irregular configurations are studied using irregularity index found in literature [17]. In both cases, Finite Element Models (FEM) represent the reference case in order to evaluate the accuracy of the EFM results. Based on the observations made in the analyses, recommendations and new criteria for improving the accuracy of EFM are proposed in both the cases of regular and irregular URM walls.

The study is here limited to the linear field, considering that both the Italian Technical Codes IBC [18] and the Eurocode [19-20] also allow the application of linear analyses for the evaluation of the seismic capacity of masonry structures. Under specific conditions regarding the stiffness of the resisting elements, both the codes allow the study of the seismic performance of masonry structures by means of linear elastic models submitted alternatively to static or modal analyses [21]. The application of a behaviour factor to the seismic actions accounts for the non-linear dissipative capacity of the material. The linear analysis of masonry structures is a rather simplistic procedure for studying masonry structures performance and thus it is affected by many limitations. However, it is still popular among professionals for studying the seismic performance of masonry structures. Despite the widespread use of linear EFMs, the available studies have not yet fully investigated their validity. The results reported in this paper represent a first step of a wider research aimed at obtaining an evaluation of the potential and limits of the EFM for both the elastic and nonlinear analyses.

\section{EQUIVALENT-FRAME MODELING OF URM WALLS}

Since its first appearance, EFM has attracted a great attention in both the scientific and professional fields. The main reason of this success has been the remarkable simplification that it allows in 
modelling the structural behaviour of masonry constructions. Before EFM formulation, the traditional modelling approaches for masonry constructions (i.e. Finite Element [22] and Discrete Element [2324] methods) entailed numerous input data and a great expertise in the management of the models. The high computational effort connected to the use of these refined methods made them convenient only for research applications or in case of complex structures [1].

The higher computational efficiency of EFM, together with its good consistency with the analysis procedures proposed by the most advanced codes [18-19, 25], has made EFM one of the most popular tools for structural modelling of masonry constructions. The rapid diffusion of this simplified method has encouraged the researchers to propose several formulations based on the equivalent frame approach, so EFM does not correspond to a unique modelling procedure.

The earliest proposals, based on the simulation of masonry walls as an assemblage of shear deformable beam elements, were written in the eighties [26]. The POR method anticipated a large series of modern EFM procedures. More recently, a great interest has raised in the modelling procedures proposed by Brencich et al. [5] and by Magenes and Della Fontana [27]. The first model, known as TREMURI [28], proposes a non-linear bi-dimensional macro-element composed by three parts to separately simulate the axial, flexural and shear deformability of masonry panels. In the second case (SAM II) [27], the seismic response of masonry walls is studied by using monodimensional elements connected by rigid end offsets. In addition to the two mentioned models, the RAN method [4] proposes the study of each load-bearing wall by applying a linear static analysis separately at each storey. The global non-linear response of the building is then derived by cumulating the non-linear ultimate capacity, floor by floor and for all the resisting walls.

All the mentioned methods propose the discretization of the masonry walls into finite macroelements, allowing contemporarily a high computational efficiency and an acceptable accuracy in simulating the main failure mechanisms of masonry panels. However, the mechanical models on which they are based present some criticalities. In particular, uncertainties can derive by the assemblage of the macro-elements in describing the stress interaction between them or in accurately reproducing the global geometrical configuration of the wall. Finally, the updating of the mechanical model with the evolution of damage is, in some cases, not completely reliable and adequate to be extended to both vertical and horizontal resisting elements (i.e. piers and spandrels).

These limitations have been dealt with a different element formulation in the approach proposed by Caliò et al. [29] and implemented in the computer code 3DMACRO [30]. The macro-element implemented in 3DMACRO is a pinned quadrilateral element delimited by rigid nodes. A set of nonlinear springs allows a reliable simulation of both the internal non-linear mechanical behaviour of the single masonry panel and the mutual interaction with the surrounding structural elements.

Casolo and Peña [31] have proposed a rigid element approach. Similarly to 3DMACRO, the model is composed of a quadrilateral rigid body with non-linear springs located at the interfaces with the adjacent macro-elements. The mechanical model reproduces the cyclic response of masonry, with specific hysteretic laws for each mechanism, allowing the simulation of the dynamic in-plane behaviour of walls.

Based on the experimental tests carried out on single masonry panels with different boundary conditions [32], the macro-elements proposed in the aforementioned EFM procedures are able to simulate adequately the in-plane response of pier panels. Indeed, once guaranteed a low probability of activation of out-of-plane mechanisms, the seismic response of the wall can be evaluated by studying the safety conditions of each pier panel with respect to all the possible failure mechanisms characterizing its in-plane behaviour. Having as reference the IBC [18] and the Eurocode [19-20], specific criteria are available for evaluating the ultimate strength of piers corresponding to both flexural and shear mechanisms: 
a) Flexural mechanism: for this mechanism the ultimate flexural strength is defined as a function of the compression force acting on the panel, the corresponding shear strength can be obtained by dividing the ultimate bending moment by the distance $h_{0}$ between the section corresponding to null value of bending moment and the pier base:

$$
\begin{aligned}
& M_{R d}=\frac{\mathrm{N} B}{2}\left(1-\frac{\sigma_{n}}{0.85 f_{d}}\right) \\
& V_{R d, \text { flex }}=\frac{M_{R d}}{h_{0}}=\frac{N B}{2 h_{0}}\left(1-\frac{\sigma_{n}}{0.85 f_{d}}\right)
\end{aligned}
$$

where: $B$ is the pier width, $\mathrm{N}$ is the axial force, $\sigma_{n}=N / B t$ is the average normal stress acting on the pier due to the applied axial force $N, f_{d}$ is the design compression strength of masonry and $t$ is the thickness of the pier.

b) Shear mechanism with diagonal cracking: in case of diagonal cracking the ultimate shear strength is defined by following the criterion defined by Turnsek and Cacovic [33]. The failure condition corresponds to the attainment of the tensile strength by the principal tension stress in the pier's central cross-section:

$$
V_{R d, d}=\frac{f_{t} B t}{\beta} \sqrt{1+\frac{\sigma_{n}}{f_{t}}}
$$

where: $f_{d}$ is the tensile strength of masonry, $t$ is the wall thickness, while $\beta$ is a non-dimensional parameter depending on the pier aspect ratio and varying between 1.0 and 1.5 [34].

c) Sliding shear mechanism: this last mechanism is based on the Mohr-Coulomb criterion that define the ultimate shear capacity as follows:

$$
V_{R d, s}=l_{c} t \cdot f_{v d}=\left(c+\mu \sigma_{n}\right) l_{c} t
$$

where: $f_{v d}$ is the design shear strength, $l_{c}$ is the length of the compressed portion of the panel's transversal section, $c$ is the cohesion, $\mu$ is the friction coefficient and $\sigma_{n}=N / l_{c} t$ is the average compression stress acting on the transversal section of the pier.

The occurrence of one among the three failure mechanisms, defined by the standards IBC [18] and Eurocode [19-20], depends on a combination of factors strictly connected to the panels' geometry (evaluated essentially in terms of slenderness), the mechanical properties, the boundary conditions and the acting axial loads.

\subsection{Macro-elements discretization of URM walls with openings}

EFM proposes the study of masonry load-bearing walls by discretizing them into finite structural elements (called macro-elements) usually modelled as one-dimensional beam elements. Three types of macro-elements compose the EFM discretization. Their geometrical properties derive simply from the extension of the openings edges, as shown in Figure 1. The extension of the vertical edges of the openings determines the identification of vertical panels (piers - Figure 1a) whose function is to carry the gravitational and horizontal loads. By extending the horizontal edges, it is possible to identify horizontal elements aimed at connecting the piers and transferring the floors loads to them (spandrels - Figure 1b). The intersection of piers and spandrels delimits the node panels (Figure 1c), modelled as fully rigid.

The frame schematization, proposed in the EFM, takes inspiration from the damages observed in masonry structures under past seismic events. The concentration of damages in piers and spandrels confirms the possibility to concentrate the wall deformation in these elements. Conversely, no damage usually affects the node panels, supporting the idea of their greater strength and stiffness. 

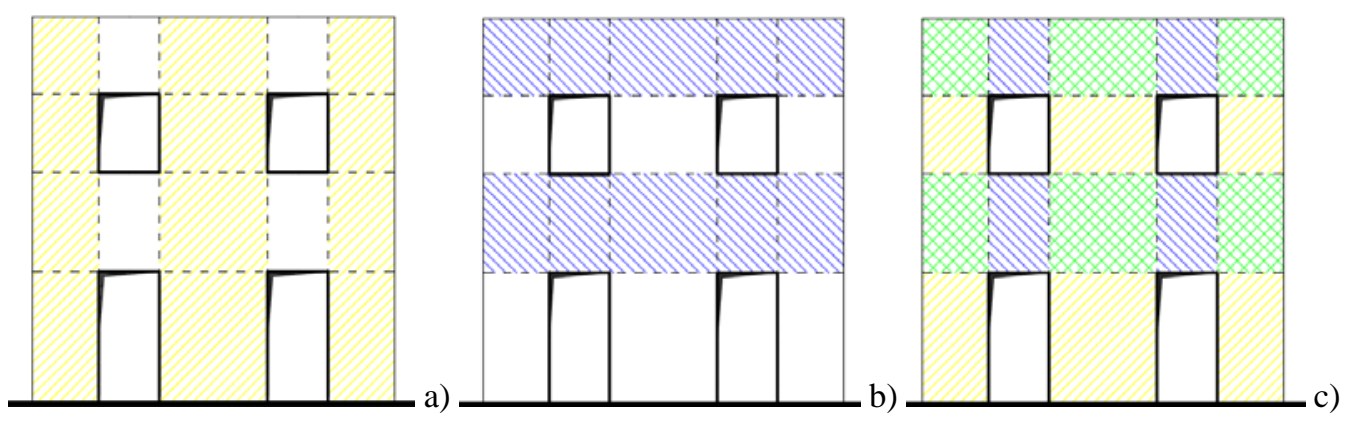

Figure 1: Discretization of a masonry façade into macro-elements: piers (a) spandrels (b) and node panels (c).

Given the frame schematization proposed by EFM, the definition of the macro-elements' geometry has a strong influence on the modelling results. In particular, the geometry of pier panels plays a crucial role since they represent the main resisting elements devoted to counteract seismic actions and transfer all the loads to the foundation system. Consequently, pier's stiffness deeply affects the total stiffness and the global seismic behaviour of the wall. The first proposals on the piers' effective height suggested the use of the openings edges as reference. The deformable height of piers was assumed equivalent to the distance between two successive horizontal edges of the openings. Two alternatives were accepted in case of openings with different height, namely to take the closest or the farthest distance between their horizontal edge lines. This simple rule was generally used in the application of the POR method [26], one of the first modelling approaches inspired to a frame discretization of masonry walls.

Trying to overcome the uncertainties in the definition of the equivalent stiffness of piers, Dolce [3] has proposed a more complex criterion for the definition of their effective height. The criterion introduced by Dolce takes into account not only the equivalent stiffness of each pier, but also the mutual interaction with the surrounding spandrels. The state of deformation affecting the spandrels can in fact result in a variable elastic restraint for the piers. This effect can consequently induce a considerable variation of the actual stiffness of piers. Based on these observations, Dolce has proposed the empirical rule reported in Eq. 5:

$$
h_{\text {eff }}=\mathrm{h}^{\prime}+\delta \frac{b\left(H-h^{\prime}\right)}{\mathrm{h}^{\prime}}=\mathrm{h}^{\prime}+\frac{b\left(H-h^{\prime}\right)}{3 \mathrm{~h}^{\prime}}
$$

where: $H$ is the interstorey height, $\delta$ is a coefficient equal to 1.3 that has been calibrated by Dolce, $b$ is the width of the pier, while $h$ ' is the distance between the midpoints of the line connecting the vertices of two consecutive openings. A limit inclination of $30^{\circ}$ is fixed for the definition of the dimension $h$ ', as shown in Figure 2a. The Eq. (5) is the result of the numerical simulation with FEM of a large number of pier-spandrel systems characterized by varying geometry and boundary conditions. The parameters introduced in Eq. (5) derive from a statistic evaluation of the equivalent stiffness of these modules. The relevance of Dolce's criterion is due to the great success that it has had among the researchers that worked with EFM approach on masonry structures. With some simplifications, it represents in fact the main reference for the frame discretization proposed by the most common EFMs currently available for URM walls.

An analogous approach to take into account the spandrels effects on the piers' stiffness has inspired the criterion contained in the FEMA 356 [35]. The spandrels work as restraints for the piers. The piers can be either double-fixed or cantilevers as a function of the spandrels' rigidity. In the case of new constructions, the FEMA 356 allows the use of the "strong spandrel and weak piers" assumption for non-linear analysis and defines the piers effective height equal to the adjacent openings height. This scheme presumes the assumption of a great rigidity for the spandrels.

The criterion proposed in FEMA 356 appears not suitable to define the equivalent static scheme in case of URM existing buildings. For these structures, the spandrels' weakness and the recurrent absence of tensile resistant elements (e.g. tie beams, timber lintels etc.) make unrealistic the 
hypothesis of effective collaboration among piers and spandrels. These conditions do not fit with the boundary conditions suggested in FEMA 356 for piers, i.e. double-fixed or cantilever.

Great uncertainties characterize also the irregular walls, where the difference between the openings' height makes more difficult the definition of the piers' height. To overcome these criticalities, Augenti and co-workers $[17,36]$ have assumed the effective height of piers as a function of the direction of application of the seismic actions. Each pier has consequently the same height of the consecutive opening from the side of the earthquake loading. The Augenti's proposal has been derived from the direct observation of recurrent damages and failure mechanisms induced by past earthquakes to ordinary masonry buildings. This criterion has found helpful confirmations in experimental tests carried out on masonry building prototypes in terms of damage distribution [3738].

In case of asymmetric or irregular walls, the application of Augenti's criterion leads to the definition of two different models for taking into account the two possible directions of seismic actions (Figure 2b). Conversely, the Dolce's criterion is completely independent of the direction of the seismic actions and thus a unique scheme is sufficient to study the in-plane behaviour of masonry walls (Figure 2a).

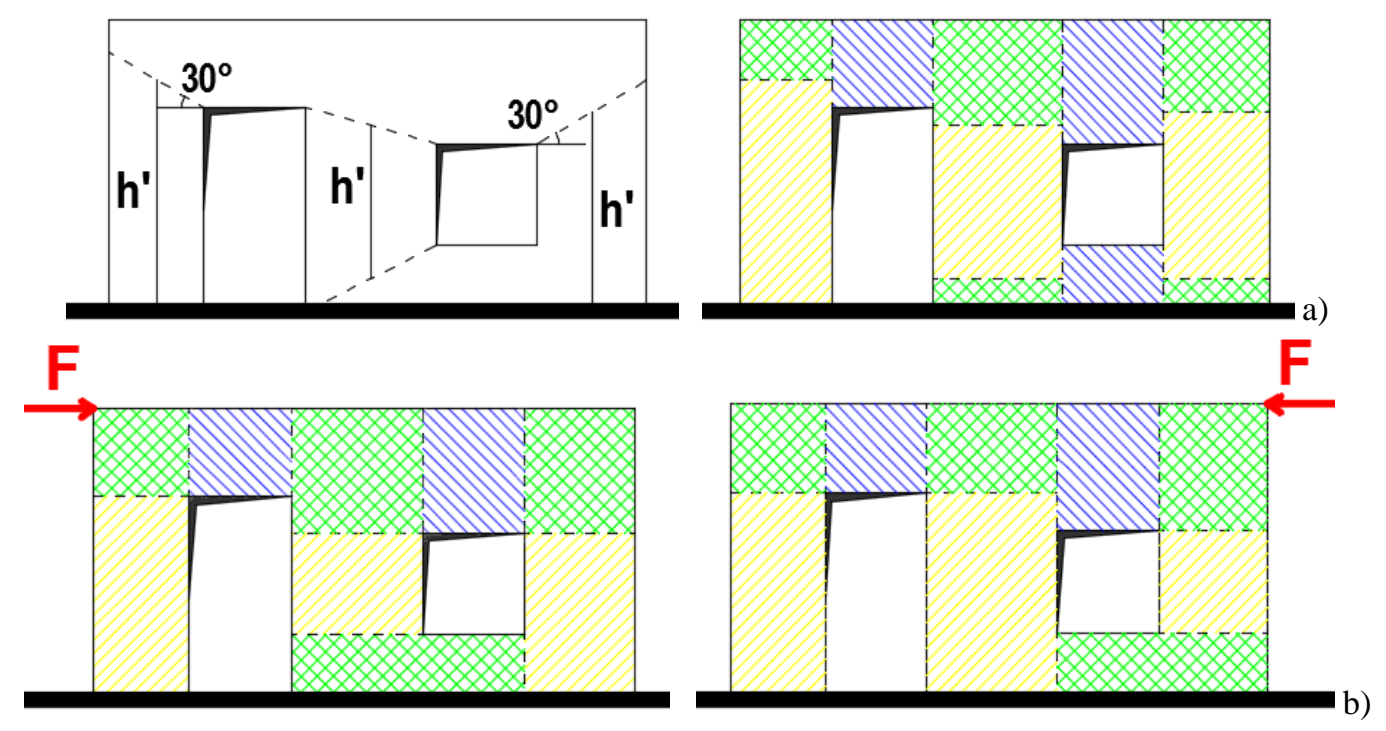

Figure 2: Criteria for the discretization of pier panels by (a) Dolce [3] and (b) Augenti [35].

The considerations made about the geometrical identification of piers have already demonstrated the important role played also by the spandrels in the frame discretization of masonry walls. Their mechanical behaviour and their deformability have a remarkable influence on the global seismic performance of the wall. Spandrels can in fact work as coupling elements and/or restraints for piers panels, determining strong variations in the static schemes of piers and hence in the global stiffness of the wall.

Two extreme static schemes can represent the in-plane behaviour of masonry walls as a function of the mutual stiffness and the strength characterizing the piers and the spandrels. The first scheme consists in strong spandrels and weak pier, so the damages are usually concentrated only in the piers. In this scheme, the spandrels work as fully rigid elements providing strong restraints to the piers. The second scheme determines a concentration of damages mainly in the spandrels, which represent the most fragile elements of the wall. In the second extreme static scheme, the spandrels provide a slight coupling effect, so the piers tend to work as cantilever beams.

Given these considerations, it is clear the importance of the structural assumptions adopted for the geometrical modelling of spandrels and the sensitivity of the results to the assumed approximation. The same applicability of EFM is conditioned by the assumptions on the spandrels. In particular, the 
IBC [18] allows the use of EFMs with collaborating spandrels only in presence of effective coupling elements. More specifically, the effective collaboration of the spandrels can be included in the models only when it is guaranteed the activation of the spandrels flexural behaviour or in presence of rigid tensile resistant elements (e.g. tie beams, timber lintels etc.).

Some additional considerations should be made about the geometric definition of spandrels. In EFM, the spandrels represent the horizontal portion of the wall included between two consecutive openings in the vertical direction. The characteristic length of the spandrels is considered equivalent to the average width of the openings including them. In case of the absence of consecutive openings in the vertical direction, the spandrel is usually removed and substitute by a rigid panel.

As for the assumption of the full rigidity of the node panels, it represents a necessary requisite for the application of EFM, but up to now only empirical observations have been used to motivate it. The greater resistance and rigidity of node panels, with respect to piers and spandrels, have been usually justified by the confinement exerted by the adjacent panels. The node panels represent the only portions of a masonry wall totally surrounded by masonry, in case of inner nodes, or surrounded along three sides, in case of edge nodes [4].

The effects of the assumptions about the spandrels and piers' geometries, as well the hypothesis of full rigidity of node panels, are still open issues. They represents besides crucial elements in the applicability of the EFM. To this regard, the observations provided in the following sections can be helpful in order to understand the importance of a consistent modelling on the accuracy of the EFM results.

\subsection{Classification and measure of the irregularity}

The study of the in-plane behaviour of URM walls is strongly dependent by their geometrical configurations. In case of URM buildings, the openings' arrangement largely contributes to determine the walls' geometrical configuration. The possible presence of misalignments among the different openings requires a clear distinction between regular and irregular configurations. URM walls can be considered regular if their openings are perfectly aligned along both the vertical and horizontal directions (Figure 3a). On the other hand, an irregular configuration has openings showing at least one misalignment [36] (Figure 3b-e).

In this paper, the distinction between regular and irregular configurations for URM walls proposed by Augenti and co-workers [35] is adopted. Their work provided one of the first systematic classifications of the irregularities recurrent in existing masonry buildings [17]. This classification includes four typologies of irregularities based on simple geometrical modifications to a reference regular multi-storey scheme. Non-dimensional indexes have been also defined in [17] to measure the amount of irregularity affecting the wall. These indexes, varying from zero to one, are used in the present study to correlate the irregularity with its effects on the modelling accuracy of EFM.

Referring to the two-storey regular wall in Figure 3a, the classification provided in [17] includes the following irregular schemes:

a) Horizontal Irregularity: at least one horizontal misalignment is present among the edges of the openings belonging to the same storey. The openings of the same storey have different heights while they conserve the same widths at the different storeys (Figure 3b). The global irregularity index for horizontal irregularity is a function of the heights characterizing openings of the same storey:

$$
i_{H}=\frac{\Delta_{H}}{2 H_{\operatorname{med}}}=\frac{H_{\max }-H_{\min }}{H_{\max }+H_{\min }}
$$

where $\Delta_{H}$ is the difference between the height of the openings belonging to the same storey, defined as the difference between the maximum $\left(H_{\max }\right)$ and the minimum $\left(H_{\min }\right)$ heights of the 
openings, as shown in Figure 3a, while $H_{\text {med }}$ is the mean of the openings' heights in a single storey.

b) Vertical Irregularity: at least one vertical misalignment is present among the edges of the openings belonging to consecutive storeys. The openings of the same storey have the same height while they have different widths at the different storeys (Figure 3c). The global irregularity index for vertical irregularity is a function of the widths of consecutive openings in the vertical direction:

$$
i_{V}=\frac{\Delta_{L}}{2 L_{\text {med }}}=\frac{L_{\max }-L_{\min }}{L_{\max }+L_{\min }}
$$

where $\Delta_{L}$ is the difference between the widths of consecutive openings from one storey to the successive one, i.e. the difference between the maximum $\left(L_{\max }\right)$ and the minimum $\left(L_{\min }\right)$ openings' widths, as shown in Figure $3 \mathrm{~b}$, while $L_{\text {med }}$ is the mean of the openings' widths.

c) Offset Irregularity: the openings have misalignments in the horizontal and/or vertical direction. The definition of this irregularity requires the individuation of the direction of the misalignment. Referring to a misalignment in the horizontal direction between two openings belonging to the same storey, the vertical distance $\left(D_{o}\right)$ between the upper edges of such openings depends of the global geometry of the storey. $D_{o}$ cannot, in fact, exceed the value $D$ - $t_{f}-H^{\prime \prime}$, where $D$ is the interstorey height, $t_{s}$ is the slab thickness and $H^{\prime \prime}$ is the height of the lower opening (see Figure 3d). Given this condition, the global irregularity index for offset irregularity in the horizontal direction can be defined as follows:

$$
i_{o, H}=\frac{\mathrm{D}_{o}}{D-t_{S}-H^{\prime \prime}}
$$

In a similar way, this work defines the global irregularity index for offset irregularity in the vertical direction. This is a novel parameter, proposed firstly in Siano [15], to complement the horizontal offset irregularity (Eq. 9) proposed by Parisi and Augenti [17]. In the case of vertical offset, the distance $D_{o}$ represents the distance between the left or right edges of consecutive openings misaligned in the vertical direction. With reference to the scheme in Figure $3 \mathrm{~d}$, the distance $D_{o}$ cannot exceeds the value $D-B_{t}-B^{\prime}$ ', where $D$ is the width of the wall portion in which the misaligned openings are included, $B_{t}$ is the thickness of the transversal wall and $B$ ', is the base of one of the two misaligned openings. The irregularity index can be specified for the case of offset irregularity in the vertical direction as follows:

$$
i_{o, V}=\frac{\mathrm{D}_{o}}{D-B_{t}-B^{\prime \prime}}
$$

d) Irregularity in the number of openings: the number of openings varies from storey to storey throughout the masonry wall (Figure 3e). The global index can be referred simply to the number of openings present in each storey as follows:

$$
i_{N}=1-\frac{N_{\min }}{N_{\max }}
$$

where $N_{\max }$ and $N_{\min }$ are the maximum and the minimum numbers of openings per storey, respectively. 

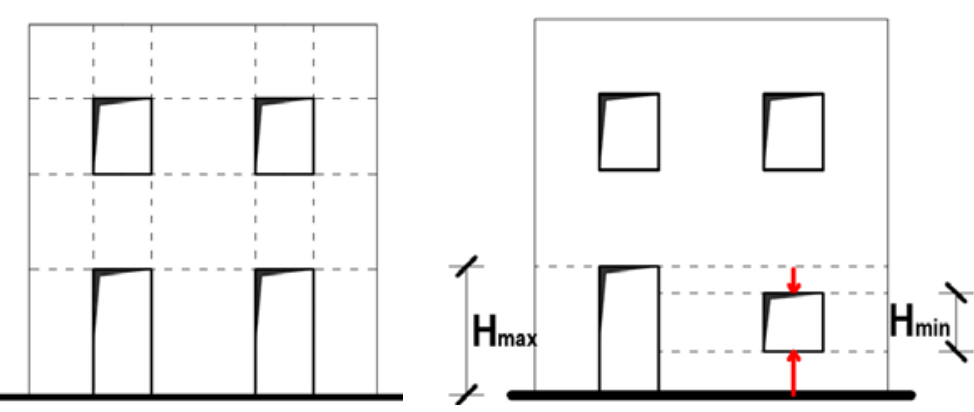

a)

b)
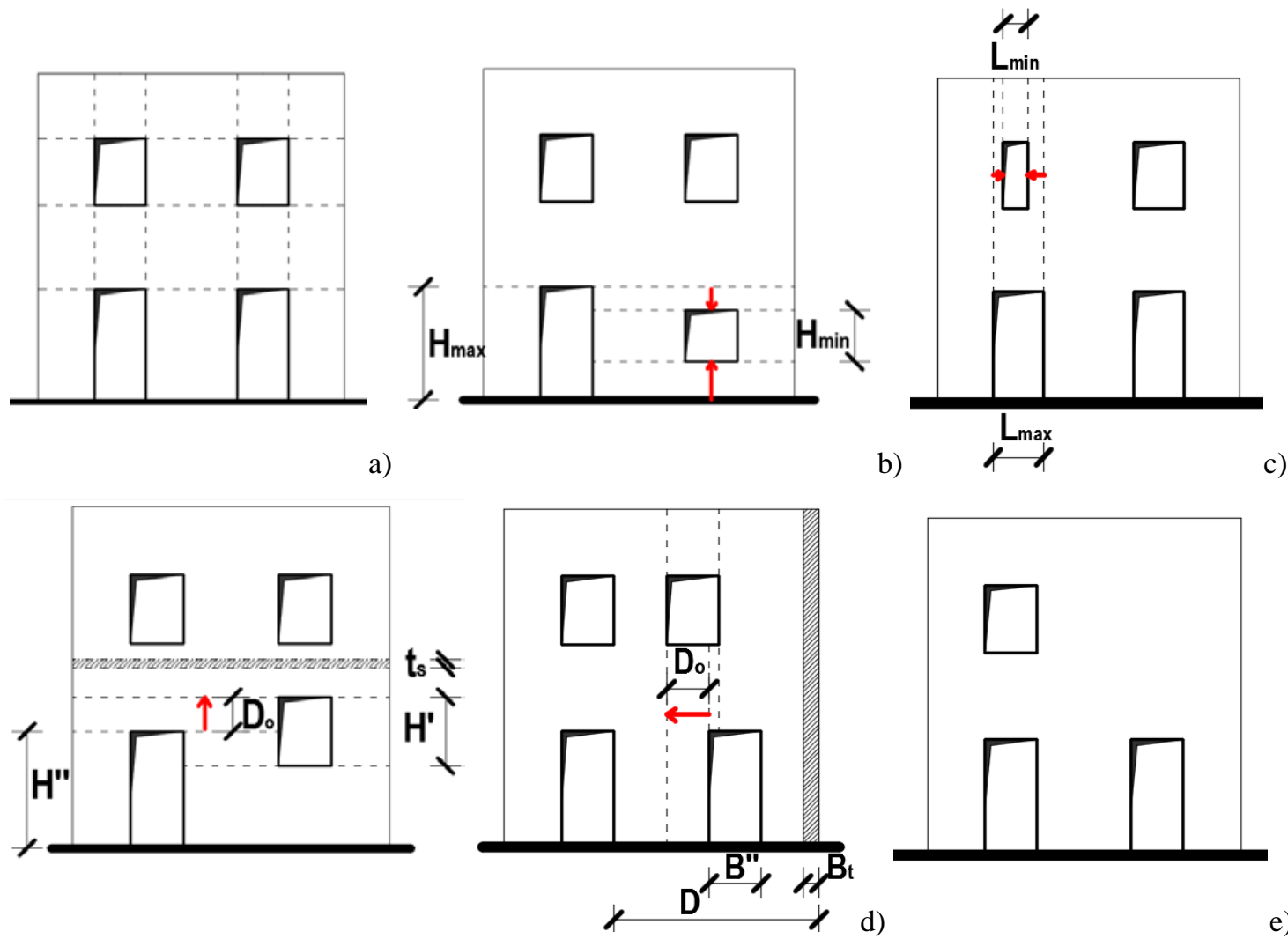

c)

e)

Figure 3: Reference regular geometry (a) and Irregularity classification according to [17]: Horizontal Irregularity (b), Vertical Irregularity (c), Offset Irregularity (d) and Irregularity in number of openings (e).

Geometrical irregularities are recurrent in both existing and new masonry buildings. In the case of existing ones (Figure 4), the irregularities derived often from the frequent structural interventions experienced by the structures along the time. Also in case of new constructions, specific structural or architectonical needs can result in an irregular arrangement of openings. The study of the effectiveness of simplified modelling methods in simulating the presence of geometrical irregularities has consequently a considerable relevance. The presence of irregularities can induce, in fact, greater uncertainties in the definition of the equivalent static schemes and reduce the effectiveness of the EFM in simulating the wall's structural performance.

The international seismic codes $[18-19,25]$ do not provide any indication about how to handle the irregularities of URM walls in structural models. A detailed evaluation of the EFM accuracy in simulating the structural behaviour of URM walls is described in the following sections for both regular and irregular geometries starting from the study of linear models, see Siano [15].
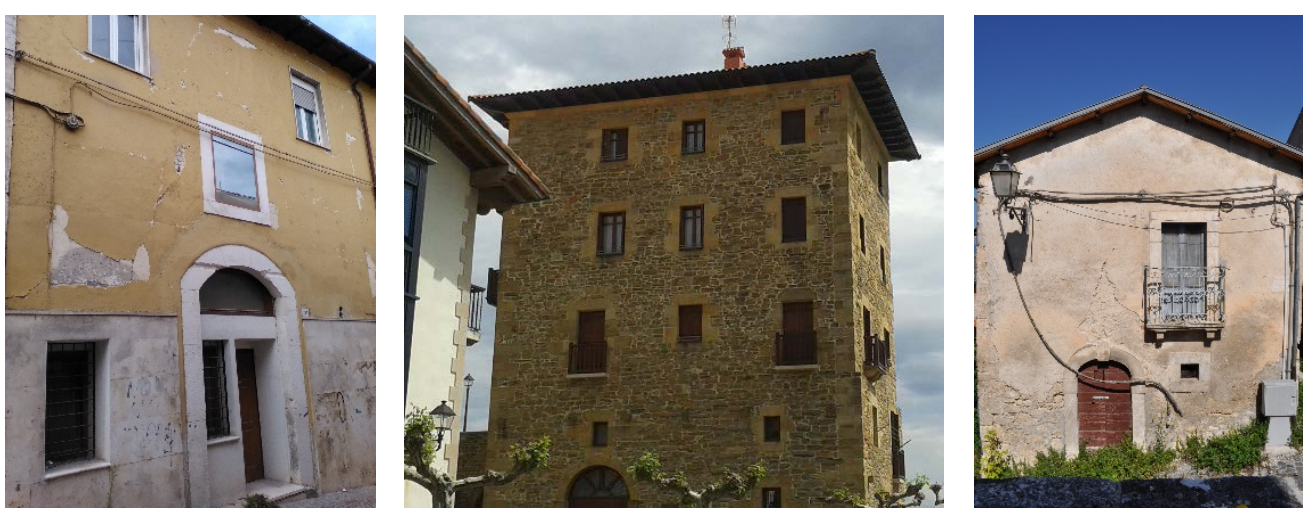

Figure 4: Examples of URM walls with irregular configurations. 


\section{NUMERICAL SIMULATION OF URM WALLS BY EQUIVALENT FRAME MODELS: ASSESSMENT OF THE MODELLING PERFORMANCE}

A wide parametric investigation was carried out to study the different geometric configurations representative of both the regular and irregular URM walls [15]. The results obtained from the parametric analyses were expressed in terms of percentage difference between the predictions provided by the EFM and the corresponding results of the FEM. The study focuses on the performance of the EFM in the linear field. The comparison between EFM and FEM results involved both forces distribution and horizontal displacements, because of their importance in the evaluation of the wall's structural performance. The differences between the predictions provided by the two modelling approaches were considered as a measure of the accuracy of the simplified EFM method.

As already stated above, both technical and economic reasons make very difficult to perform comprehensive experimental campaigns with a wide set of geometrical configurations. A possible alternative to obtain reference results to be compared with EFM is considering refined FEM numerical models. The high level of accuracy that characterize the FEM, confirmed by a large number of advanced simulations of experimental tests available in literature [7, 39-43], can guarantee the completeness and reliability of the results presented here.

Each investigated wall was discretized into masonry panels according to the criteria of Dolce [3] and Augenti [27]. The objective is to analyse different modelling assumptions, given the crucial importance of the variation of the piers' effective height in the results of the EFM.

\subsection{Calibration of models and parameters for measuring EFM accuracy for regular walls}

The first step in the evaluation of the modelling accuracy of EFM consisted in the study of regular URM walls. The parametric investigation presented herein involves a wide set of different geometrical configurations studied in linear field. Starting from a regular reference wall (Figure 5), different geometrical schemes were obtained by progressively changing the dimensions of the structural elements of the wall (piers and spandrels). Each scheme was modelled both with FEM and EFM and the results of the linear static analyses were compared to measure the differences between the two methods. As shown by Figure 5, the reference wall was a two-storey scheme with global dimensions $6.00 \times 6.43 \mathrm{~m}^{2}$ and a constant thickness of $0.60 \mathrm{~m}$.
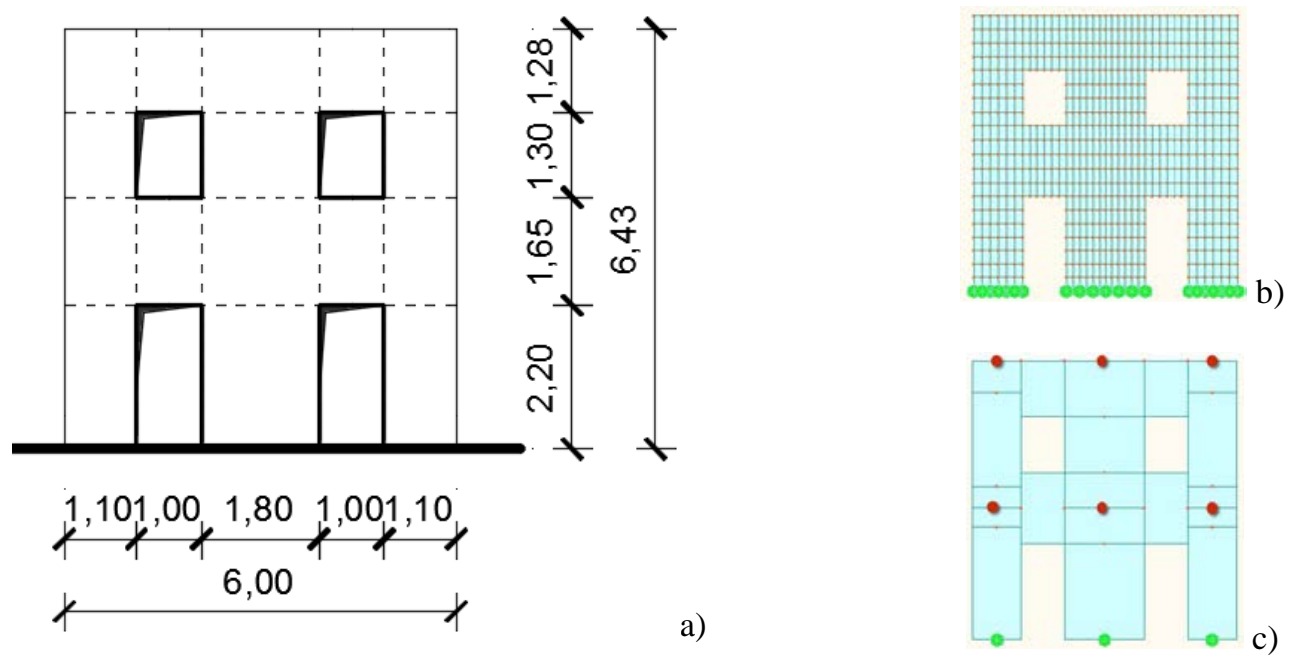

Figure 5: Geometry of the reference wall (a) and corresponding numerical models with FEM (b) and EFM (c).

The linear frames consisted in piers and spandrels modelled as one-dimensional beam elements connected by rigid links. This configuration reproduced the main assumptions on which the EFM 
approach is based. The FEM models were built by discretizing each wall into rectangular plane stress elements. The FEM and EFM linear analyses were implemented by using the software MIDAS GEN (C) [44] with the same properties, loads and boundary conditions. Specific parametrical checks about the degree of refinement of FEM allowed minimizing the influence of meshing size on the results. For all the selected geometrical configurations, FEM models with increasing level of meshing accuracy were tested to identify the optimum level of discretization.

The gravity loads transmitted by the floors were defined with reference to common RC floor systems. The total weight of this structural system was equal to $3.55 \mathrm{kN} / \mathrm{m}^{2}$, the weight of nonstructural components was $2.40 \mathrm{kN} / \mathrm{m}^{2}$ and the live loads were $2.00 \mathrm{kN} / \mathrm{m}^{2}$, according to residential use [18]. All these loads were considered applied on over a transversal depth of $2.00 \mathrm{~m}$. The seismic actions were modelled according to a distribution of horizontal forces proportional to the first mode of vibration of the wall. The horizontal forces were distributed over each node of the models to avoid stress concentration and minimize any difference in the EFM and FEM. The same mechanical and loading models were replaced for all the geometrical schemes tested.

Table 1 resumes the mechanical properties used for the implementation of the numerical models. In particular, $E$ is the Young's modulus, $G$ is the shear modulus, $\gamma$ is the density of the material, while $v$ represents the Poisson's ratio.

Table 1: Mechanical properties assumed for masonry in the parametric analysis.

\begin{tabular}{cccc}
\hline E [MPa $]$ & G $[\mathrm{MPa}]$ & $v[-]$ & $\gamma\left[\mathrm{kN} / \mathrm{m}^{3}\right]$ \\
\hline 1500.0 & 625.0 & 0.2 & 18 \\
\hline
\end{tabular}

Looking to the reference scheme reported in Figure 5a, it is evident the strong correlation existing between the openings' dimensions and the geometric configurations of piers and spandrels. Every change in the openings' width or height induces a mutual and multiple variations of piers' and spandrels' dimensions. This can lead to very complex parametric analysis in which the number of changing dimensions is very high and the interpretation of the results can be ambiguous. With the intent to simplify the procedure, the derivation of all the possible schemes from the reference one was done by minimizing as much as possible the number of varying dimensions. More specifically, the geometrical schemes were defined by varying separately the openings' width or height. To clarify the procedure, Figure 6 shows the dimensions fixed (in black) and the varying ones (in red and blue).
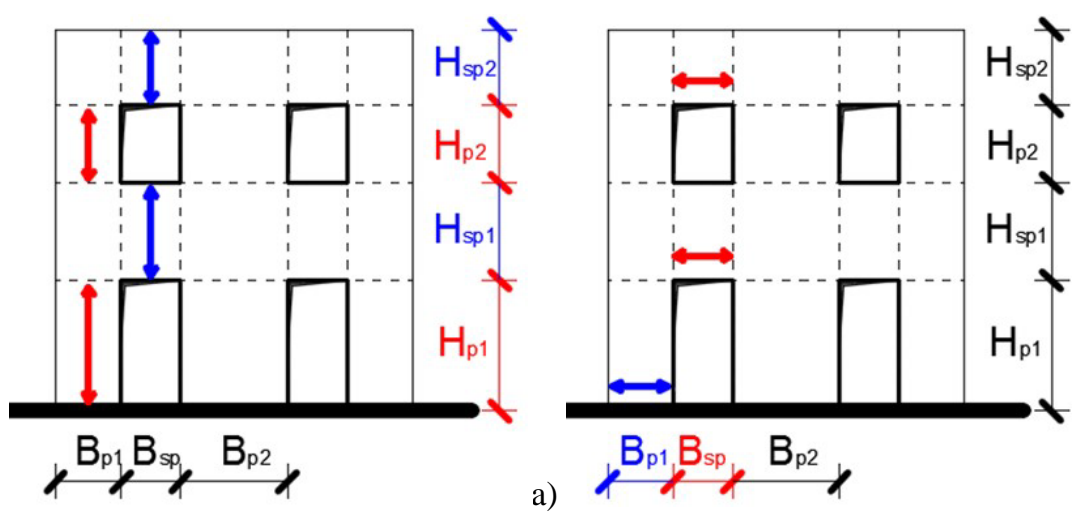

b)

Figure 6: Identification of the varying geometrical dimensions on the reference wall to derive all the different structural schemes for the parametric analysis. 
In a first stage, the heights of the openings were assumed as varying dimensions (red dimensions in Figure 6a). The progressive variation of the openings' height induced the corresponding variation of the height of spandrels and piers for both the levels (blue dimensions in Figure 6a). No changes involved the openings' width that remained constant (black dimensions in Figure 6a). Further models were defined in a second stage by applying a progressive variation only to the width of the openings (Figure 6b), maintaining constant their height. In this stage, the width of the edge piers was varied only, while the central pier width was maintained constant as a further simplification. Finally, the two procedures for the definition of the different structural schemes were mixed to extend the set of samples. Figure 7 and Figure 8 show some of the models derived by varying respectively the height and the width of the openings in the reference wall.
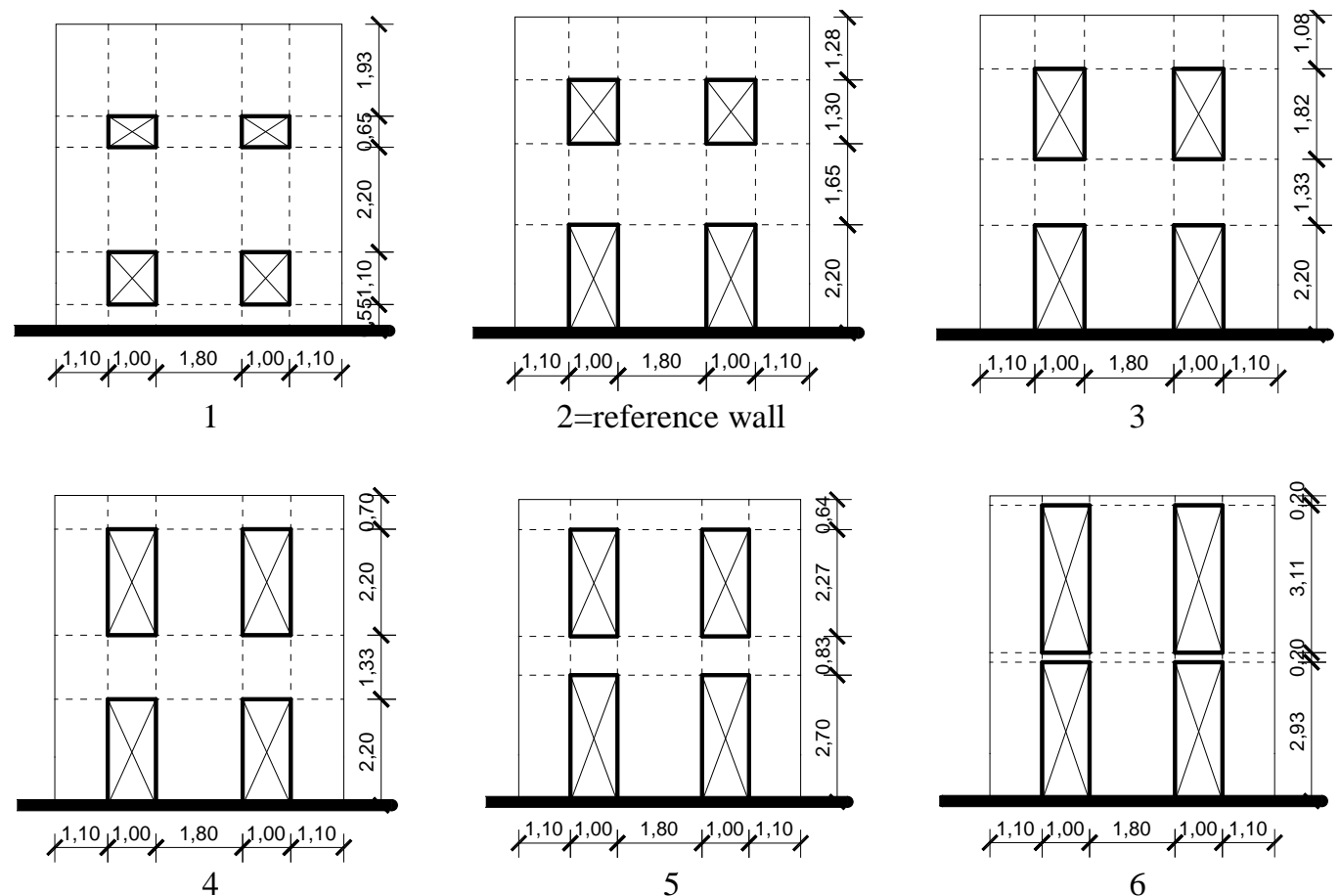

Figure 7: Examples of structural schemes obtained by varying the height of the openings in the reference wall.
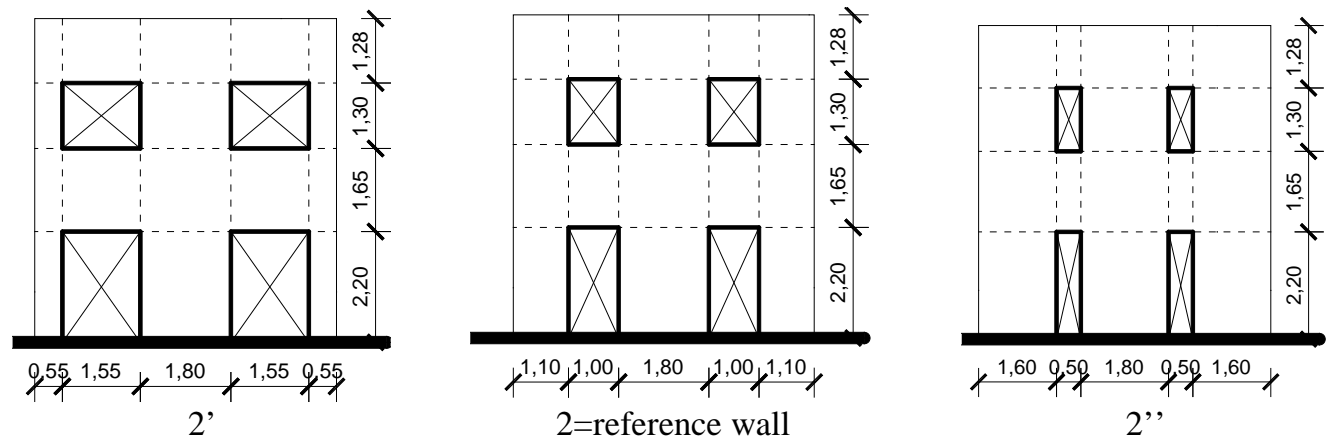

Figure 8: Examples of structural schemes obtained by varying the width of the openings in the reference wall.

Once defined all the geometrical schemes, non-dimensional parameters were defined to describe and interpret the results of the parametric analysis. The parameters proposed in Siano [15] are aimed at quantifying the similarity between the URM wall and an equivalent plane frame. These parameters interpret the results of the parametric analysis with the aim to measure the degree of consistency between the structural behaviour of the URM wall and its corresponding frame configuration. Taking into account the main assumptions of the EFM approach, the numerical distinction between frame- 
like and non-frame-like configurations was expressed as a function of the relative dimensions of the resisting masonry panels. The following non-dimensional parameters are introduced:

a) Geometrical Ratio $\left(\rho_{I}\right)$ : for a given pier, $\rho_{I}$ represents the mean of the ratios between the moments of inertia of the pier and of the adjacent spandrel, calculated at each storey. This geometrical ratio can be calculated for a two-storey wall as follows:

$$
\begin{aligned}
\rho_{I} & =\frac{1}{2}\left[\left(\frac{I_{s p, 1} / B_{s p}}{I_{p} / H_{p 1}}\right)+\left(\frac{I_{s p, 2} / B_{s p}}{I_{p} / H_{p 2}}\right)\right]=\frac{1}{2}\left[\left(\frac{I_{s p, 1} H_{p 1}}{B_{s p} I_{p}}\right)+\left(\frac{I_{s p, 2} H_{p 2}}{B_{s p} I_{p}}\right)\right]=\frac{I_{s p, 1} H_{p 1}+I_{s p, 2} H_{p 2}}{2 B_{s p} I_{p}}= \\
& =\frac{1}{2 B_{s p}} \cdot \frac{12}{t B_{p 1}^{3}}\left(\frac{t H_{s p 1}^{3}}{12} H_{p 1}+\frac{t H_{s p 2}^{3}}{12} H_{p 2}\right)=\frac{H_{s p 1}^{3} H_{p 1}+H_{s p 2}^{3} H_{p 2}}{2 B_{s p} B_{p 1}^{3}}
\end{aligned}
$$

where $I_{s p}=t H_{s p}{ }^{3} / 12$ and $I_{p}=t B_{p}{ }^{3} / 12$ are the moment of inertia of the spandrel and pier's sections, respectively, $t$ is the wall thickness, $H_{s p}$ is the height of the spandrel and $B_{p}$ is the pier width.

b) Slenderness Ratio $\left(\rho_{S}\right)$ : for a given pier, $\rho_{S}$ is the sum of the inverses of the products between the slenderness ratios of each pier and the adjacent spandrel, calculated for each storey of the wall. The slenderness ratio can be calculated for a two-storey wall as follows:

$$
\rho_{S}=\left(\frac{1}{\lambda_{\mathrm{sp}, 1} \lambda_{\mathrm{p}, 1}}+\frac{1}{\lambda_{\mathrm{sp}, 2} \lambda_{\mathrm{p}, 2}}\right)=\left[\left(\frac{\mathrm{H}_{\mathrm{sp}, 1} B_{p}}{B_{s p} H_{\mathrm{p} 1}}\right)+\left(\frac{\mathrm{H}_{\mathrm{sp}, 2} B_{p}}{B_{s p} H_{\mathrm{p} 2}}\right)\right]=\frac{B_{p}}{B_{s p}}\left(\frac{\mathrm{H}_{\mathrm{sp}, 1}}{H_{\mathrm{p} 1}}+\frac{\mathrm{H}_{\mathrm{sp}, 2}}{H_{\mathrm{p} 2}}\right)
$$

where $\lambda_{s p}=B_{s p} / H_{s p}$ and $\lambda_{p}=H_{p} / B_{p}$ are respectively the slenderness ratios of spandrel and pier, $H_{s p, i}$ and while $B_{s p}$ are respectively the height and the width of the spandrel for each storey, respectively, while $H_{p, i}$ and $B_{p}$ are the height and the width of the edge pier for each storey.

Figure 9 reports the variations of the two non-dimensional parameters defined by the Eq. (11) and (12) as function of the total width of the piers and the total height of the spandrels for all the investigated structural configurations. The values of the non-dimensional parameters are normalized with respect to the value corresponding to the reference wall. A monotonic trend characterizes the variation both the parameters for an assigned dimension. When varying one of the dimensions reported in one of the axes of the graphs, a decreasing trend of either $\rho_{I} / \rho_{I \text {, ref }}$ or $\rho_{S} / \rho_{S, \text { ref }}$ indicates a better consistency between the structural scheme of the URM wall and the corresponding frame configuration.
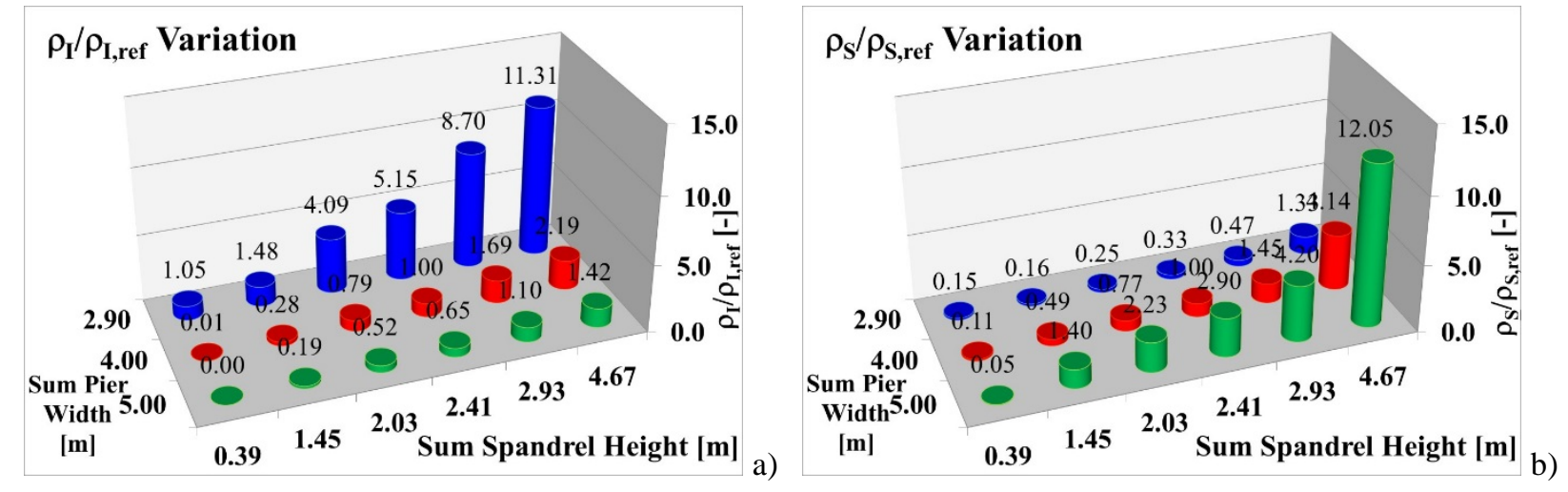

Figure 9: Variation of the parameters $\rho_{\mathrm{I}} / \rho_{\mathrm{I}, \text { ref }}(\mathrm{a})$ and $\rho_{\mathrm{S}} / \rho_{\mathrm{S} \text {,ref }}$ (b) for the studied structural schemes.

\subsection{Results of the Sensitivity analyses}

Figure 10 shows the results obtained for models that differ only in the height of the openings, while all the other geometrical dimensions remain fixed. The graphs express the relationship between the non-dimensional parameter $\rho_{I}$ (defined in Eq. (11)) and the percentage differences between EFM and FEM results for the base shear and the horizontal displacement of the pier on the left side of the wall. The different modelling performances are shown for the two criteria of definition of the piers' 
effective height. Figure 10 shows trends indicating the greater effectiveness of Augenti's criterion [26] than Dolce's criterion [3] in predicting the forces distribution among the piers. Almost negligible errors, with respect to FEM results, characterize in fact the EFM models defined according the Augenti's criterion in the prediction of the base shear. On the other hand, the models defined according to Dolce's criterion show lower errors in the prediction of the horizontal displacements. Analogous results were found also in the comparative analyses carried out by Marques and Lourenco [13].
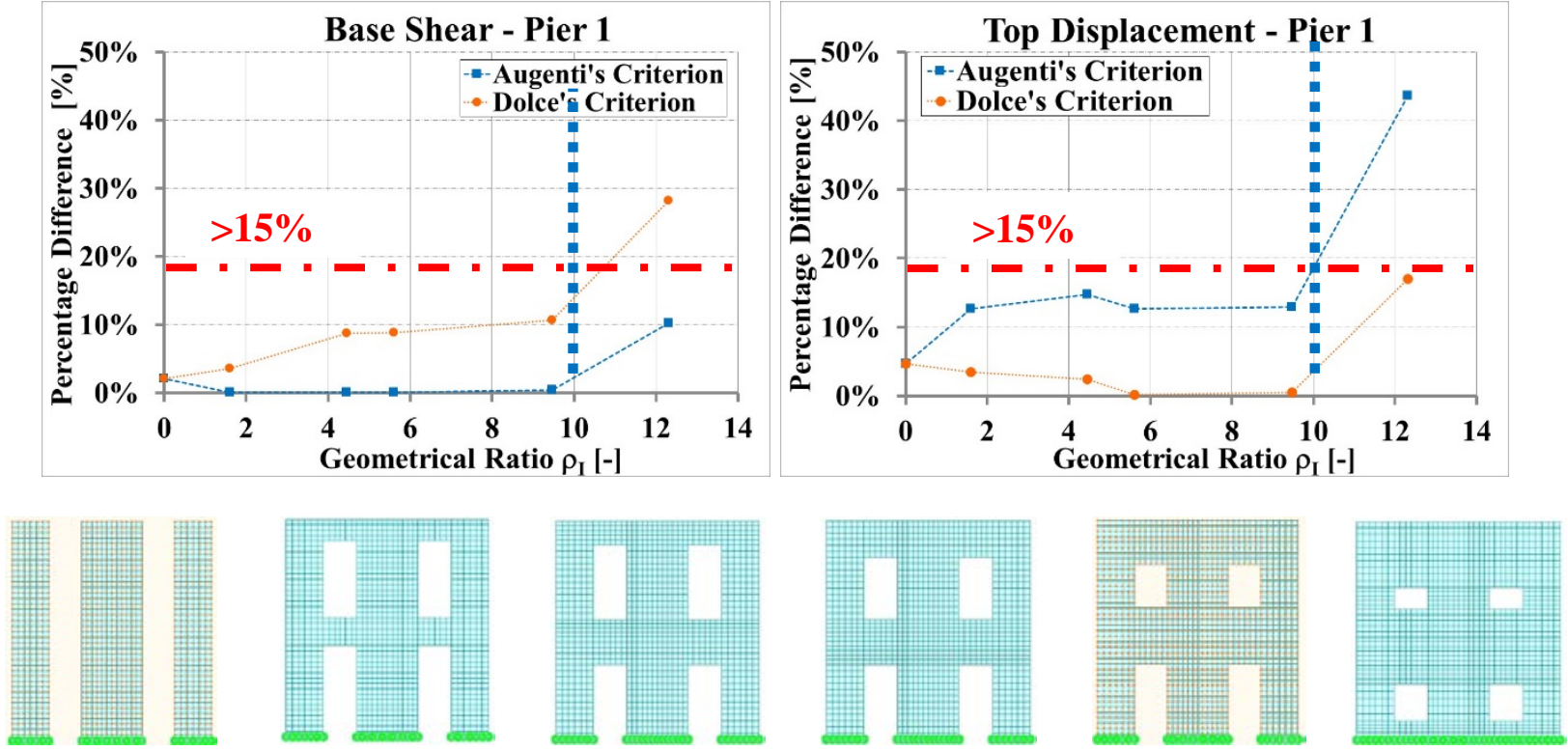

Figure 10: Percentage difference between EF and FE results for Base Shear and Top Displacement of the left Pier.

The observed performances are consistent with the theoretical bases of the two criteria. The Dolce's criterion derives in fact by equivalent stiffness considerations among EF and FE models. Dolce considered a principle of statistic equivalence between the elastic stiffnesses of EF and FE models to derive the effective heights in a set of pier-spandrel schemes. The use of the stiffness control can easily explain the better behaviour of Dolce's assumption for displacements' predictions. On the other hand, the criterion provided by Augenti was proposed to reproduce the damage suffered by existing masonry constructions under seismic actions and therefore provides better results for the evaluation of the strength.

Figure 10 shows also a progressive reduction of the affinity with an ideal frame configuration as the parameter $\rho_{I}$ increases. This means that the error associated to the EFM predictions increases for models characterized by a very low similarity with a frame configuration. These results confirm the possibility to assume $\rho_{I}$ as a reliable measure of the affinity between the URM wall and an equivalent frame. A similar trend was found for the parameter $\rho_{s}$ although not reported here.

The results obtained suggest also some specific indications for what concerns the limits of applicability of EFM to regular masonry walls. By fixing an acceptable limit for the difference between EFM and FEM predictions, it is then possible to define clear limits for the EF approach in terms of limit values of $\rho_{I}$ and $\rho_{S}$. For the two-floor walls considered here, a difference greater than $15 \%$ is found between the EFM and FEM predictions when the stiffness ratio $\rho_{I}$ is greater than 10 . This result shows the possibility to have a reference value of $\rho_{I}$ to delimit the range of applicability of the EF approach for the case of regular masonry walls. This reference value could be obviously further calibrated by considering different structural configurations of URM walls, e.g. with more pier panels and more storeys. 
The observations made for the models of Figure 10 can be extended to all the other models of the parametric analysis. Figure 11 and Figure 12 show the results obtained for all the models as function of the total width of the piers and the total height of the spandrels. By comparing these results with those reported in Figure 9, similar monotonic trends can be observed both for the parameters $\rho_{I}$ and $\rho_{S}$ and for the differences between EFM and FEM predictions. This evidence confirms that $\rho_{I}$ and $\rho_{S}$ are suitable parameters to quantify the consistency between the structural configuration of a URM wall and its corresponding EFM model.
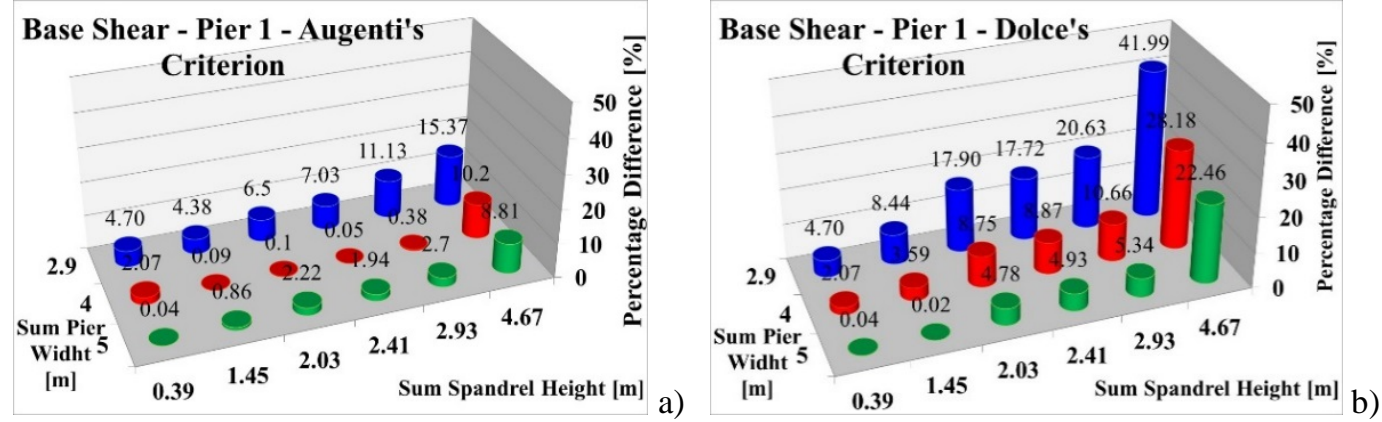

Figure 11: Percentage difference between EFM and FEM for base shear on the left pier for Augenti's (a) and Dolce's (b) criteria.
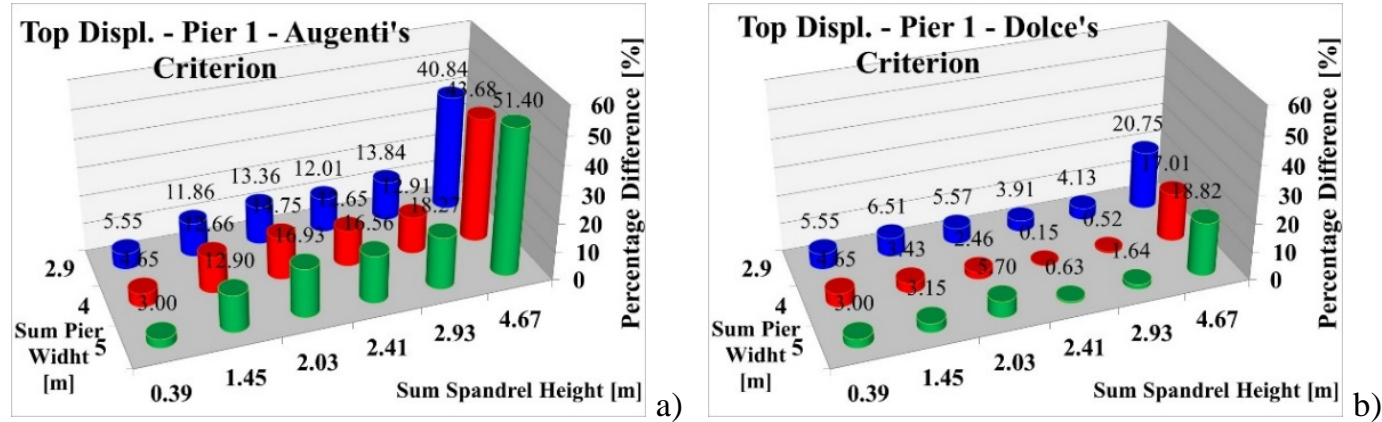

Figure 12: Percentage difference between EFM and FEM for top displacement on the left pier for Augenti’s (a) and Dolce's (b) criteria.

\subsection{Evaluation of the irregularity effects on EFM accuracy}

An analogous approach was followed to verify the accuracy of EFM for URM walls characterized by irregular configurations. Following the irregularity classification of Section 2.3 provided by Parisi and Augenti [17], a comparative study between EFM and FEM was carried out. The objective is the evaluation of the effect of the irregularities on the accuracy of the EFM for the different classes of irregularity described in Section 2.3. The irregularity indexes defined by Parisi and Augenti [17] allowed the identification of a correlation between the amount of irregularity in the wall and the accuracy of EFM in predicting its structural performance.

The different structural schemes were derived by applying increasing amount of irregularity to the same regular wall. The reference wall was a two-storey scheme characterized by global dimensions $8.60 \times 7.20 \mathrm{~m}^{2}$ and a constant thickness equal to $0.40 \mathrm{~m}$. The reference wall had a perfect symmetry, equal inter-storey height and equal height for all the piers. These geometrical assumptions simplified a lot the definition of the piers' effective height according to the two criteria applied in the present work, i.e. Augenti's and Dolce's. This approximation also guaranteed an easier introduction of irregularities into the reference structural scheme.

The properties, boundary and loading conditions were the same used in Section 3.1 for the regular configurations. All the models were studied in the linear field by applying linear static analyses with a distribution of horizontal forces proportional to the first mode of vibration of the wall. 


\subsubsection{Linear Models for Horizontal Irregularity}

The horizontal irregularity corresponds to the presence of misalignments in the horizontal direction between the openings belonging to the same level [17], as discussed in Section 2.3. This determines uncertainties in the definition of the effective height of the piers, resulting in a possible strong alteration of the equivalent frame scheme. The modelling of existing buildings with horizontal irregularity requires a careful modelling due to the uncertainties related to the involved structural members. As already highlighted in Parisi and Augenti [17], existing buildings present in many cases windows with parapets having a smaller thickness or characterized by a lower degree of interlocking. For all these cases, a careful assessment should be necessary in order to detect the actual structural configuration of masonry walls.

Starting from the regular reference scheme, the presence of horizontal irregularities were studied by testing several irregular geometries characterized by an increasing irregularity index (Eq. 6). The irregularity index varied from 0.00 to 0.67 for the tested geometries. The effects connected to the location of the irregularity at both the storeys of the wall were also studied, as shown in Figure 13.

Figure 14 and Figure 15 show the percentage differences between EFM and FEM results as a function of the global irregularity index for irregularity located at the $1^{\text {st }}$ and at the $2^{\text {nd }}$ level. The results regard the prediction of the base shear and the displacement of each pier at both the storeys. The results show the absence of mutual influences by the irregularities from storey to storey. In both the cases of walls with irregularity located at the $1^{\text {st }}$ and $2^{\text {nd }}$ storey, the presence of the irregularity in a single storey is able to reduce the accuracy of the EFM results only in the same storey. No appreciable variations characterize the results provided by EFM for the storey in which the openings are perfectly aligned.

A decrease of the accuracy of the results provided by EFM, with respect to FEM, affects the walls characterized by horizontal irregularity at the $1^{\text {st }}$ storey as the irregularity index increases. For these investigated geometries, errors greater than $20 \%$ characterize both shear and displacements predictions. A lower sensitivity to the irregularity characterizes the walls characterized by horizontal irregularity at the $2^{\text {nd }}$ storey. The presence of horizontal irregularity at the base of the wall strongly modifies the boundary conditions of the equivalent frame scheme, if compared with the regular configuration. This can motivate the greater scatter between EFM and FEM in case of irregularity at the base of the wall than in case of irregularity at the upper levels. The trends observed confirm the possibility to use the irregularity index (provided in [17]) as measure of the modelling accuracy of EFM. By fixing a tentative limit of 15\% for the acceptable scatter between EFM and FEM, problems of applicability of EFM arise for an irregularity index equal to 0.25, at least for walls characterized by irregularity at the first level.

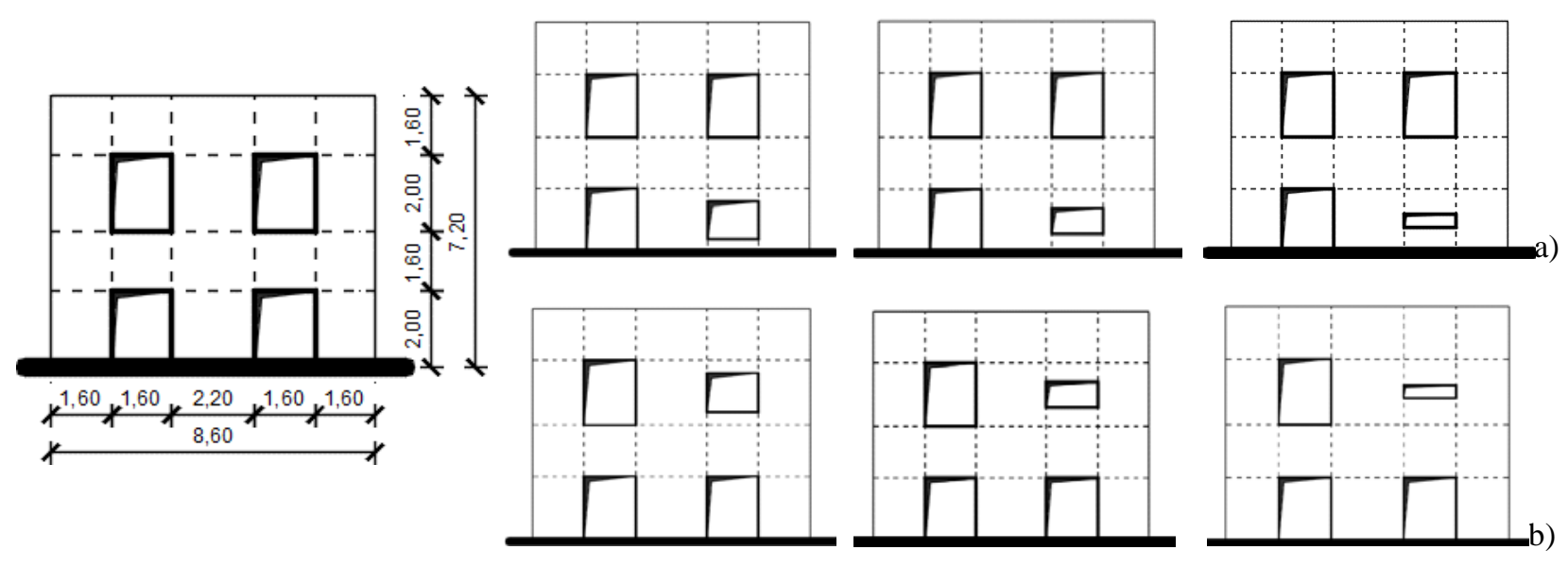

Figure 13: Geometry of the walls with horizontal irregularity at $1^{\text {st }}(\mathrm{a})$ and $2^{\text {nd }}(\mathrm{b})$ storey. 

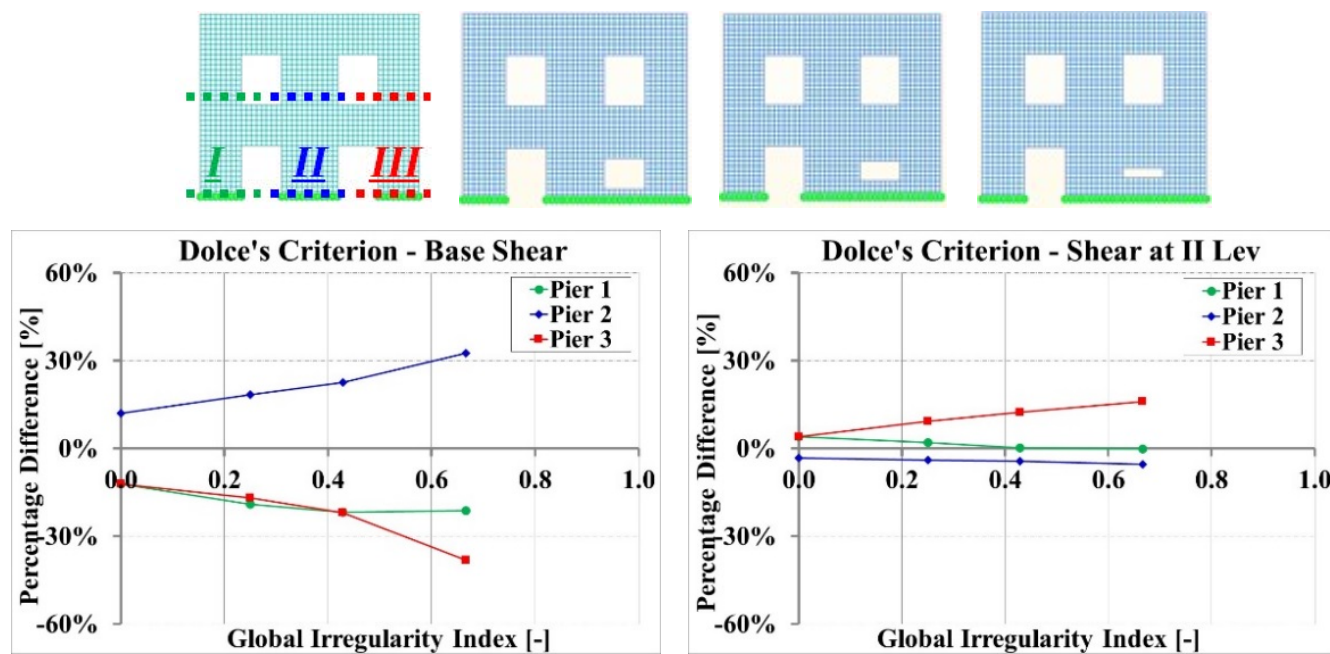

a)
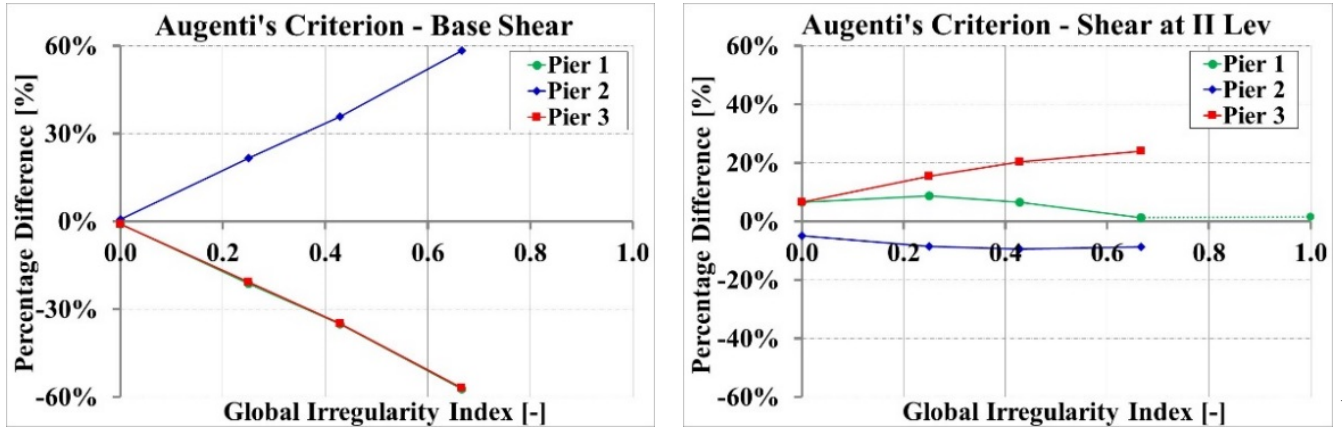

b)

Figure 14: Percentage difference between FEM and EFM for shear with Dolce's (a) and Augenti’s (b) criteria for walls with horizontal irregularity at the $1^{\text {st }}$ storey.
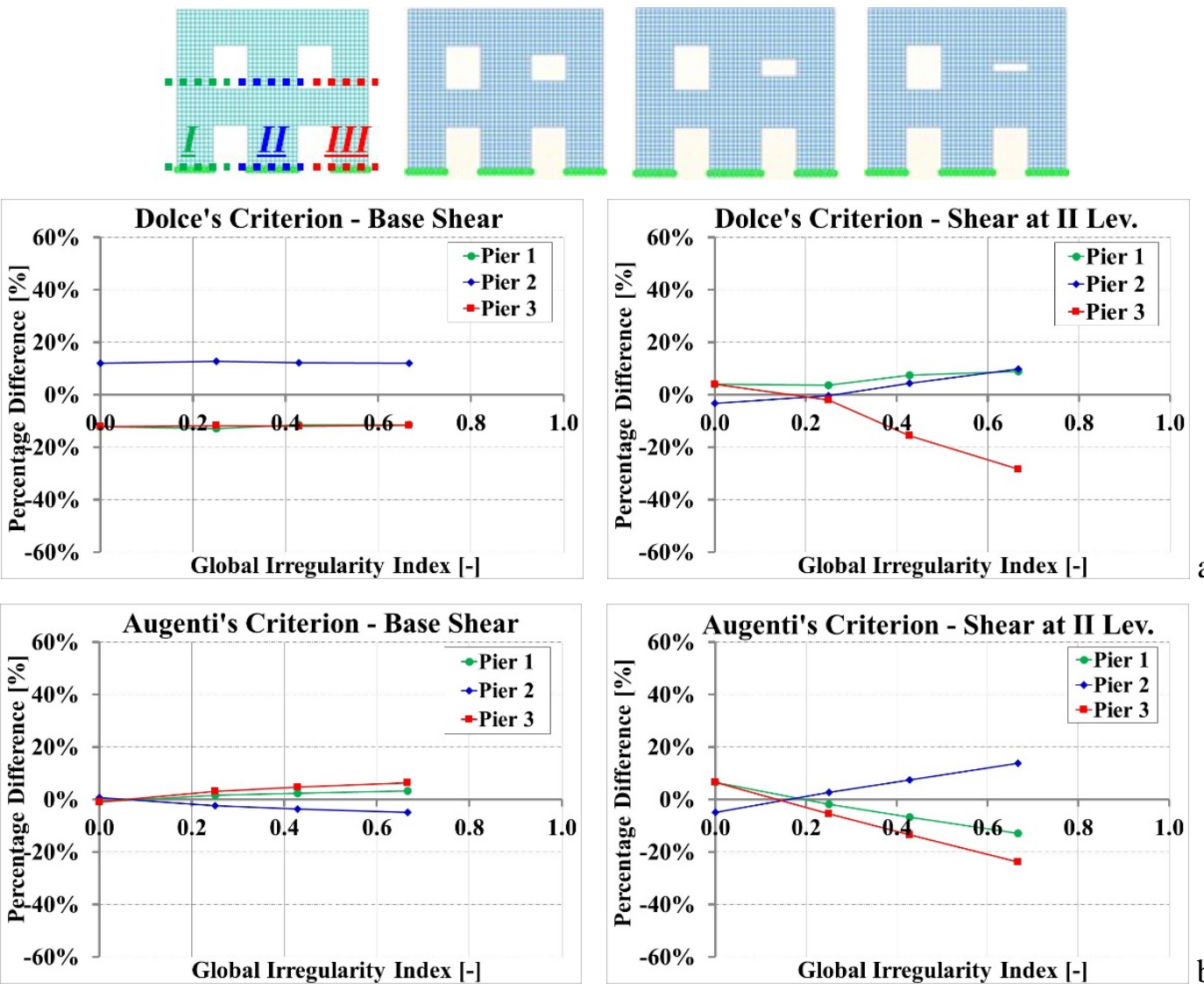

a)

Figure 15: Percentage difference between FEM and EFM for shear with Dolce’s (a) and Augenti's (b) criteria for walls with horizontal irregularity at the $2^{\text {nd }}$ storey. 
Following the provisions provided by the IBC [18] to check the safety conditions of masonry walls, the effects produced by the irregularity were evaluated also in terms of safety coefficients. For all the piers of the irregular schemes tested here, the strength domains corresponding to the flexural ( $M-N$ domain) and shear ( $V-N$ domain) failure mechanisms were defined according to the criteria described in section 2. Then the coefficients corresponding to the safety conditions of each pier were computed as the ratio between the internal forces and their ultimate strength. The following safety coefficients can be obtained for flexural and shear failure mechanisms, respectively:

$$
\begin{aligned}
& \gamma_{\text {flex }}=\frac{\mathrm{M}_{s d}}{M_{u}} \\
& \gamma_{\text {shear }}=\frac{V_{s d}}{\min \left(\mathrm{V}_{\text {flex }} ; V_{u, d}\right)}
\end{aligned}
$$
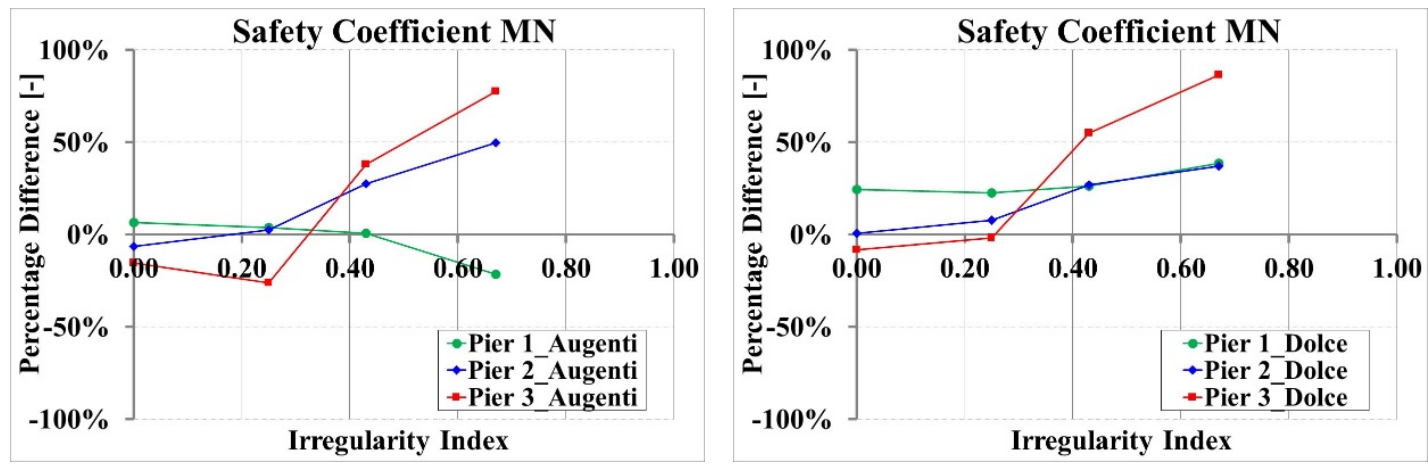

Figure 16: Percentage difference between the safety coefficients provided by EFM and FEM models for flexural mechanisms (Eq. 13) as a function of the irregularity index.
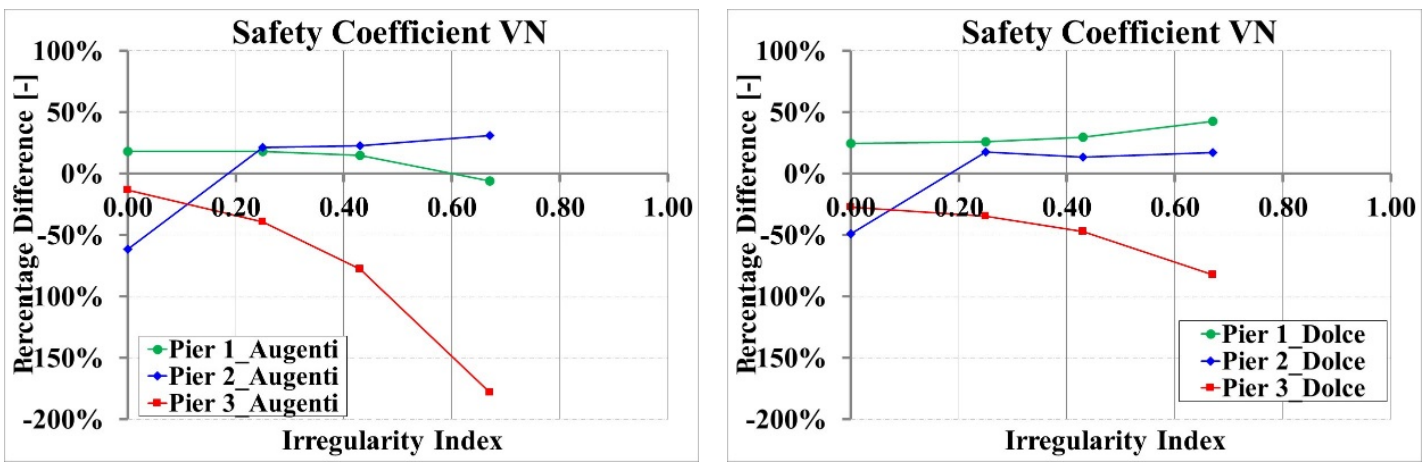

Figure 17: Percentage difference between the safety coefficients provided by EFM and FEM models for shear mechanisms (Eq. 14) as a function of the irregularity index.

Figure 16 and Figure 17 show the percentage differences between the safety coefficients predicted by EFM and FEM for flexural (Eq. 13) and shear (Eq. 14) mechanisms, respectively. These results are expressed as a function of the irregularity index for the walls affected by irregularity at the $1^{\text {st }}$ storey. An increase of the difference between the safety coefficients provided by the two modelling approaches is found for increasing irregularity index. These increasing errors provided by EFM results are slightly mitigated only in the case of the pier 1 for which the geometrical properties are not changing in the models tested. The results provided by EFM present a remarkable error with respect to FEM. Moreover, the EFM prediction is not always more conservative than the FEM simulation, therefore a great attention should be paid to improve the EFM models for this specific investigated problem.

\subsubsection{Comparison of Linear Models for different irregularity categories}

The study of the effects of the geometrical irregularity on the EFM modelling involved all the typologies identified in [17]. A comparison of the effects produced by each category of irregularity was carried out with the aim to identify those connected with the greatest criticalities. A great 
attention was concentrated on the three categories determined by misalignments among the openings, namely horizontal, vertical and offset irregularities. By assuming a fixed value of the corresponding irregularity indexes, a series of comparison among irregular geometries for the aforementioned categories allowed to understand better the way in which they influence the accuracy of the modelling results.

Figure 18 shows an example of three irregular geometries. These schemes are representative of URM walls affected by horizontal, vertical and offset irregularity, respectively. Starting from a single regular configuration (Figure 18a), the same value of the irregularity index $\left(i_{H}=i_{V}=i_{o, H}=0.40\right)$ is used to derive each irregular scheme. In all the cases, the irregularity is concentrated at the first level of the wall due to the greater sensitivity of the modelling results for schemes characterized by irregularities at the first storey.
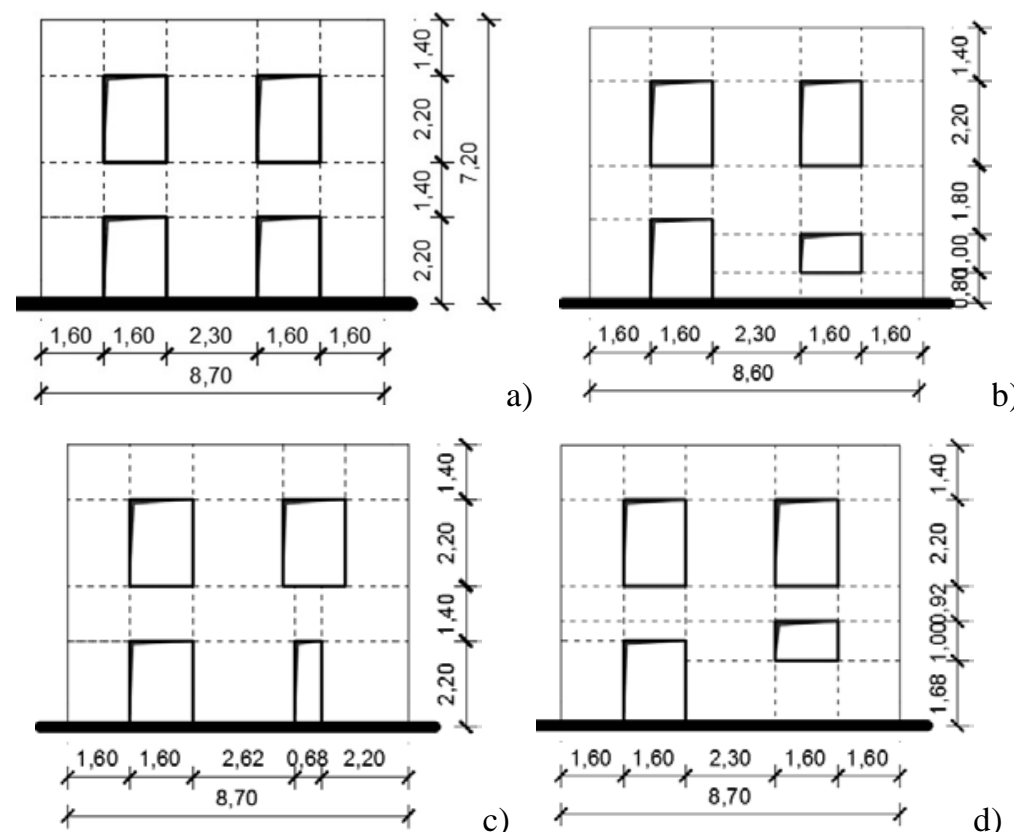

Figure 18: Reference regular geometry of a wall with two rows of openings (a) and geometries of the walls with irregularity $\left(i_{H}=i_{V}=i_{o, H}=0.40\right)$ : horizontal irregularity (b), vertical irregularity (c) and offset irregularity (d).

Clear indications can be derived about the modelling uncertainties by comparing the results provided by the EFM models for each irregular scheme. Figure 19 and Figure 20 show the percentage differences between EFM and FEM results for each pier of the tested walls. The figures show both the distribution of base shear among the piers and the absolute horizontal displacements. The results obtained for the three irregular schemes are also compared with the results related to corresponding regular scheme. The scatters between EFM and FEM increase for all the types of irregularity with respect to the reference regular configuration. This indicates the worsening effect exerted by the irregularities on the EFM's capability to simulate the structural performance of URM walls. At the same time, a different sensitivity of the results characterizes each category of irregularity. In particular, lower uncertainties affect the vertical irregularity with respect to the other categories. The errors made by EFM for the scheme with vertical irregularity are not negligible but at the same time are always lower than the errors observed for the schemes affected by horizontal or offset irregularity. This last scheme in particular shows the greatest errors with respect to the FEM predictions for both the base shear forces and the displacements.

The results obtained confirm one more time the strong influence of the effective height of piers on the modelling results. Both the irregularities of horizontal misalignment and offset between the openings determine a strong alteration of the piers' effective height. In the case of vertical irregularity, 
the effects are concentrated on the definition of the effective width to assign to the spandrels included in-between the misaligned openings.
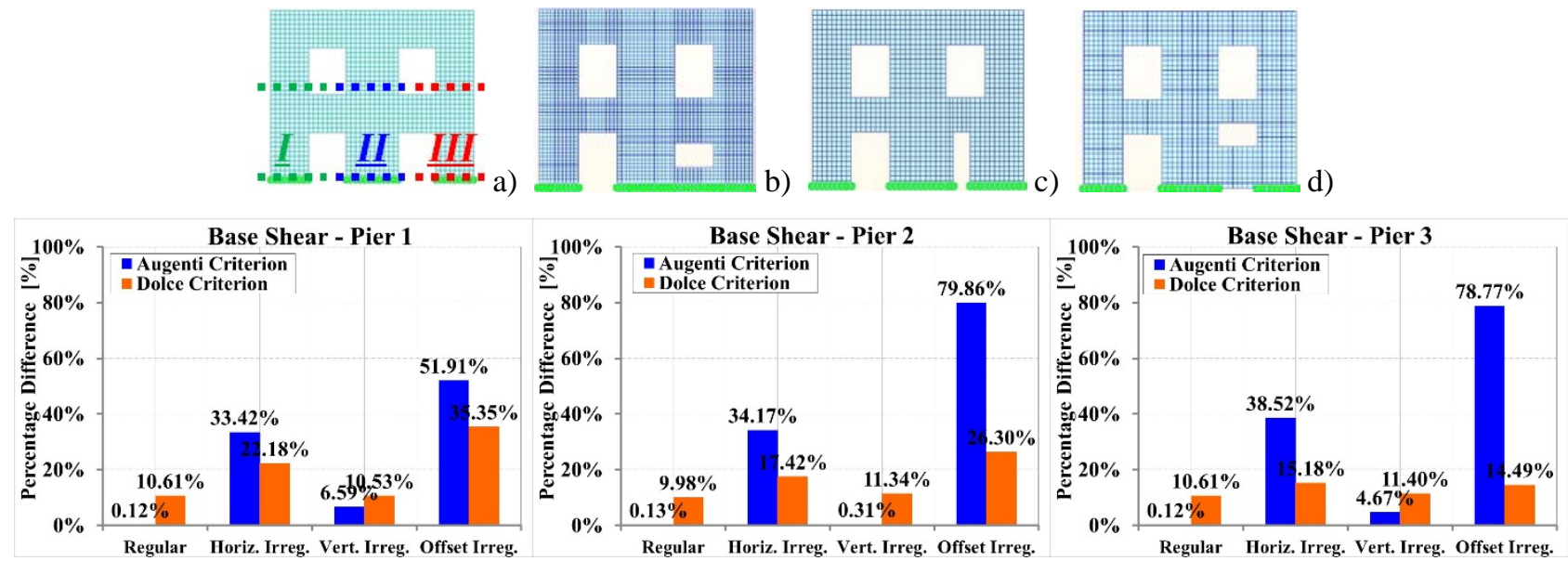

Figure 19: Percentage difference for Base Shear for a regular wall with two rows of openings (a) and corresponding walls characterized by horizontal (b), vertical (c) and offset irregularity (d). Case of irregularity indexes $i_{H}=i_{V}=i_{o, H}$ $=0.40$.
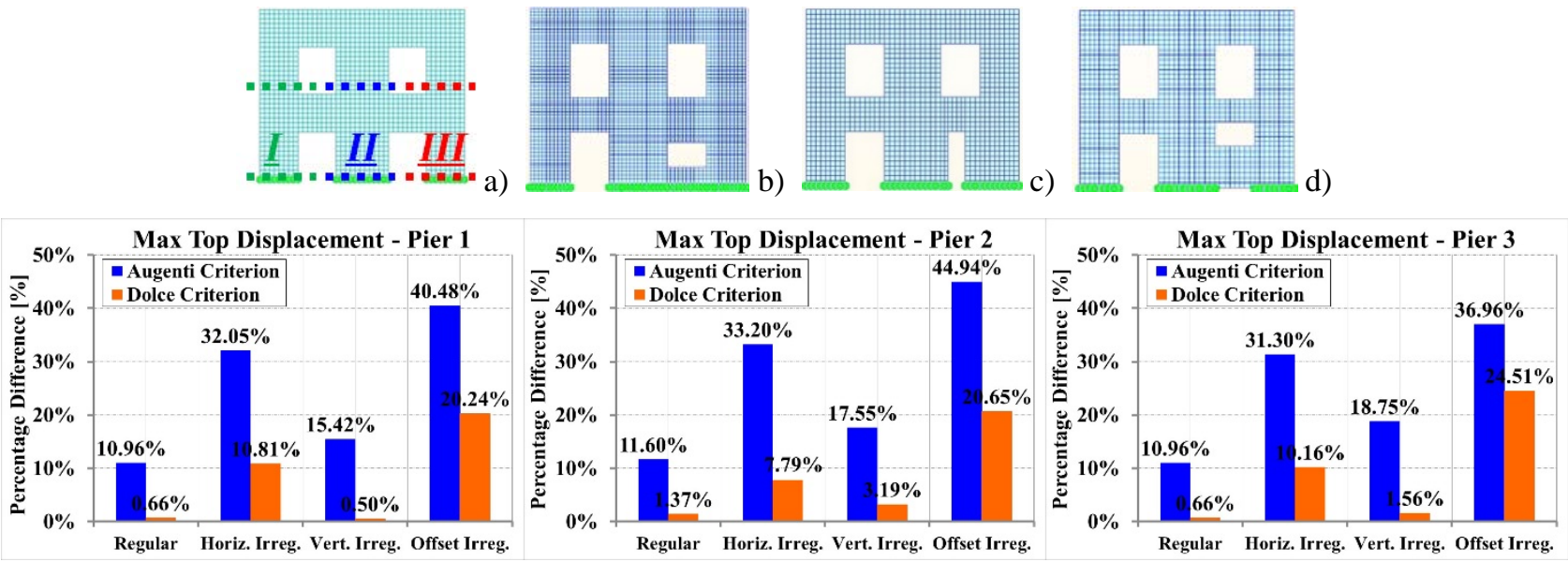

Figure 20: Percentage difference for Top Displacements for a regular wall with two rows of openings (a) and corresponding walls characterized by horizontal (b), vertical (c) and offset irregularity (d). Case of irregularity indexes $i_{H}=i_{V}=i_{o, H}=0.40$.

The evaluation of EFM accuracy was then extended to more complex geometries by considering as reference scheme a regular wall with two floors and three rows of openings. Similarly to the wall with two floors and two rows of openings, three irregular schemes were derived by the reference regular one (Figure 21a) by applying the same value of the irregularity index $\left(i_{H}=i_{V}=i_{o, H}=0.40\right)$ for different types of irregularity (Figure 21b,c,d). Also for the case of walls with three rows of openings, the irregularity was located at the first level. In this way it was possible not only to compare the effects of different types of irregularity on the EFM accuracy, but also to investigate how its accuracy varies with the numbers of piers.

Figure 22 and Figure 23 reports the percentage differences between EFM and FEM base shear and horizontal displacements for each pier of the walls under consideration. The results obtained for walls with three rows of openings confirm the trends observed in walls with two rows of openings. In particular, an increase of the scatters between EFM and FEM results characterize all the types of irregularity with respect to the regular scheme. A different performance of EFM models can be observed in the cases of walls with openings vertically or horizontally misaligned. The horizontally misalignment leads to remarkable differences between EFM and FEM results. Conversely, the effects 
of vertical irregularity seem almost negligible in both the cases of walls with two and three rows of openings.
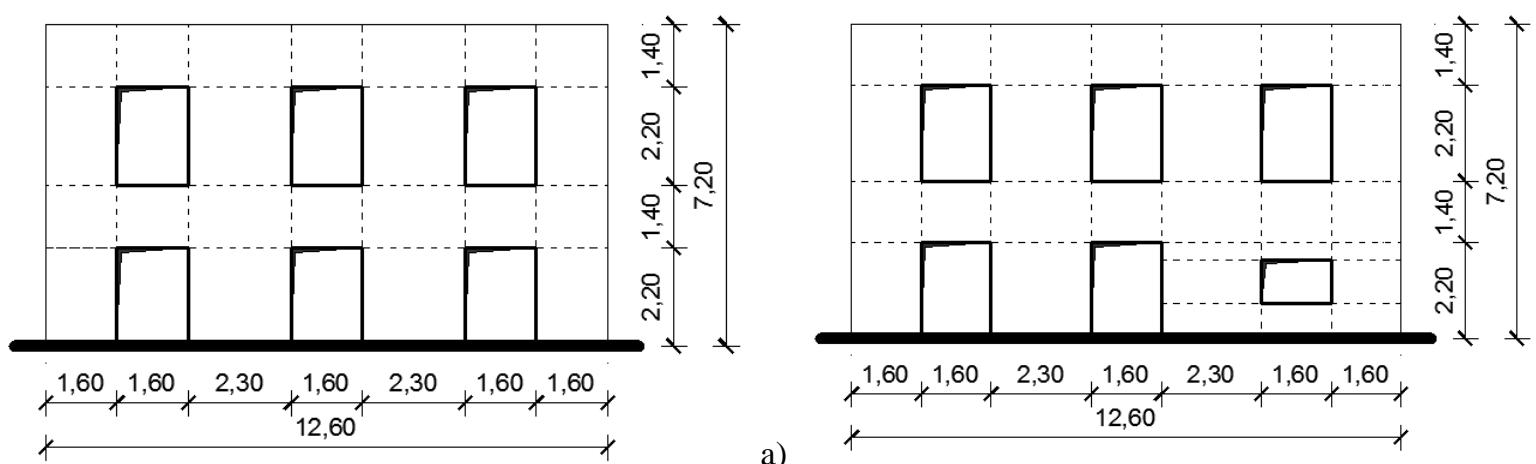

b)
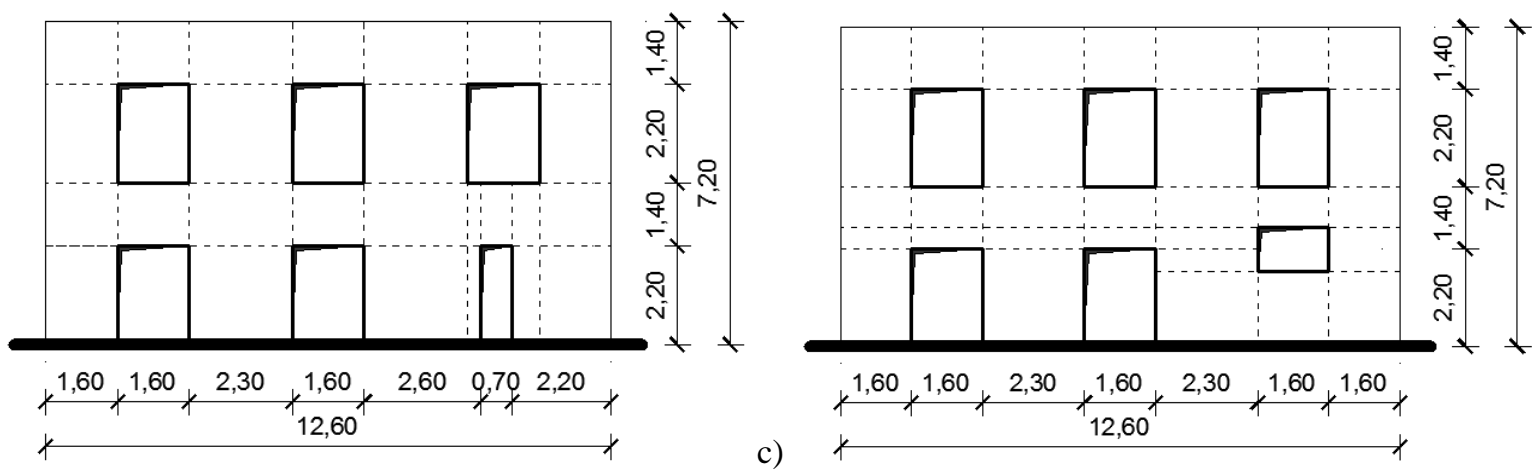

d)

Figure 21: Reference regular geometry of a wall with three rows of openings (a) and corresponding walls with irregularity $\left(i_{H}=i_{V}=i_{o, H}=0.40\right)$ : horizontal irregularity (b), vertical irregularity (c) and offset irregularity (d).
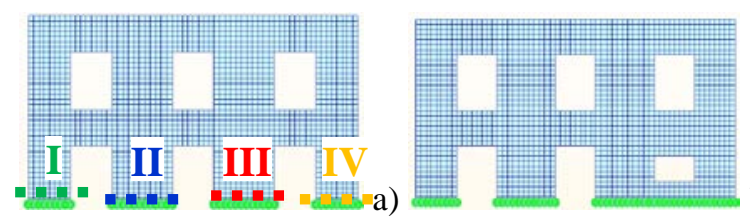

b)
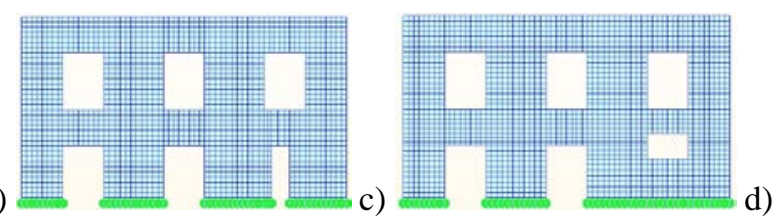

Base Shear - Pier 1
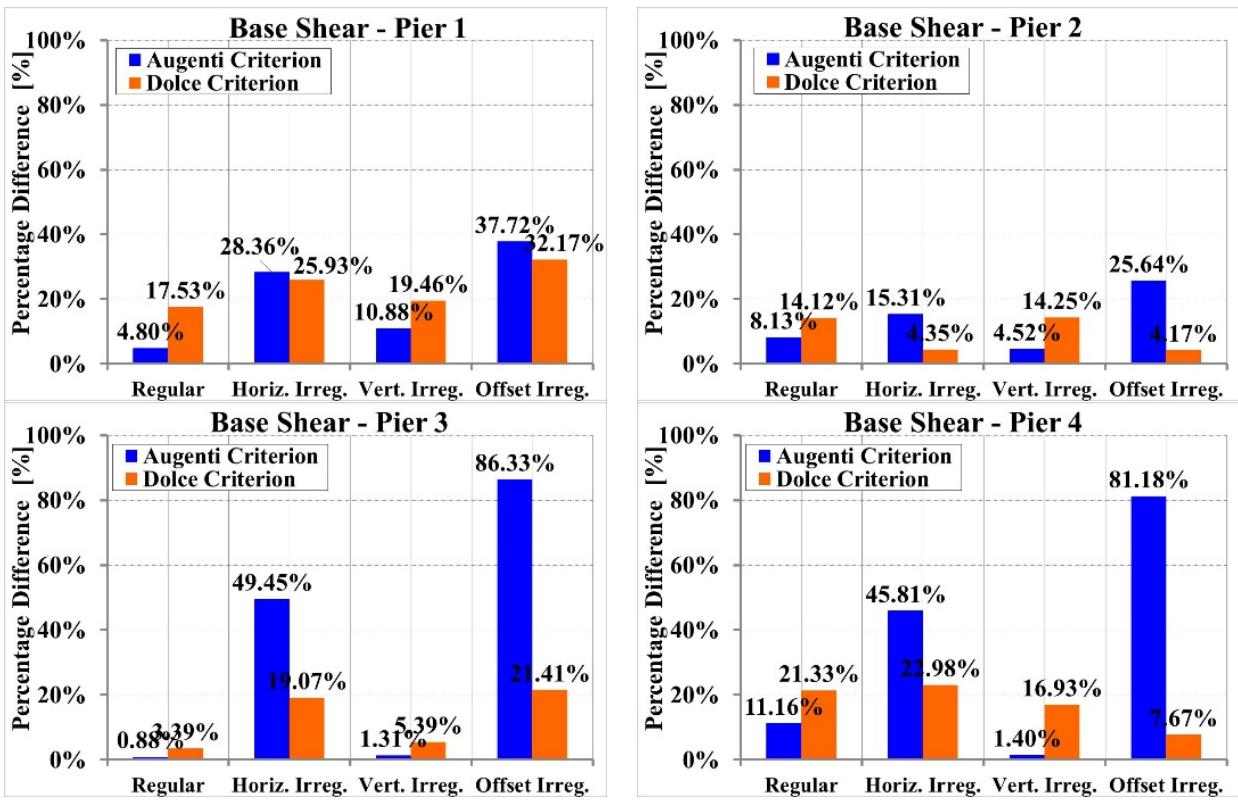

Figure 22: Percentage difference for Base Shear for a regular wall with three rows of openings (a) and walls characterized by horizontal (b), vertical (c) and offset irregularity (d). Case of irregularity indexes $i_{H}=i_{V}=i_{o, H}=0.40$. 

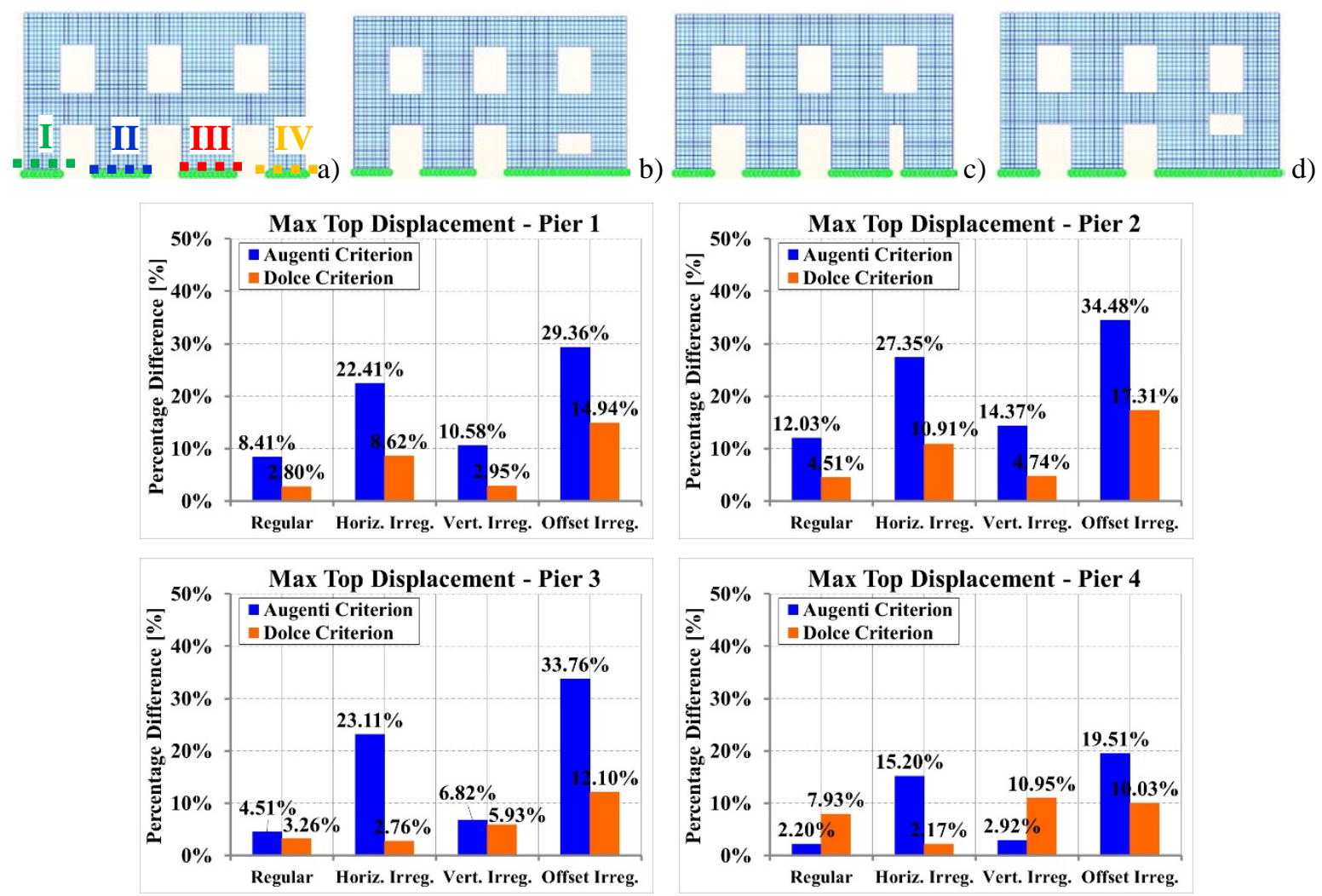

Figure 23: Percentage difference for Top Displacements for a regular wall (a) and walls characterized by horizontal (b), vertical (c) and offset irregularity (d). Case of irregularity indexes $i_{H}=i_{V}=i_{o, H}=0.40$.

\subsubsection{Linear Models for Irregularity in the Number of Openings}

The irregularity in the number of openings is very common in the existing masonry buildings and often produced by the continuous modification that such buildings undergo over the time. This category can induce modelling problems in particular for what concerns the connections between deformable beam elements adopted to simulate piers and spandrels. The absence of a window alters significantly the ideal frame configuration because it is not possible to made a clear distinction among the frame elements in the portion of the wall without the window. To overcome this anomaly, the most common modelling procedures based on EFM propose to model all the portion of the wall without the window as a unique pier, as shown in Figure 24. The macro-pier inserted into the model is usually connected to the remaining part of the frame by means of large rigid zones.

The solution shown in Figure 24b is reasonable from a static point of view to recompose the ideal frame, but it seems not applicable to all the cases of irregular walls. First of all, the assumption of fully rigidity of the masonry panels below the macro-pier at the $2^{\text {nd }}$ storey appears not fully justified in case of larger openings at the $1^{\text {st }}$ storey, due to the higher deformability that will consequently characterize the spandrels above them. For these cases, the tension flow above such openings could be transmitted effectively in case of the presence of tie beams, timber lintels or other tension-resistant elements. This means that the assumptions of fully rigidity for the panels under consideration should be carefully verified by studying the actual structural behaviour of each single case. Finally, it is also important to underline that the macro-pier will tend to move as a rigid block, inducing an overestimation of the tension stresses in the piers of the $1^{\text {st }}$ storey when the wall is subjected to seismic actions. 

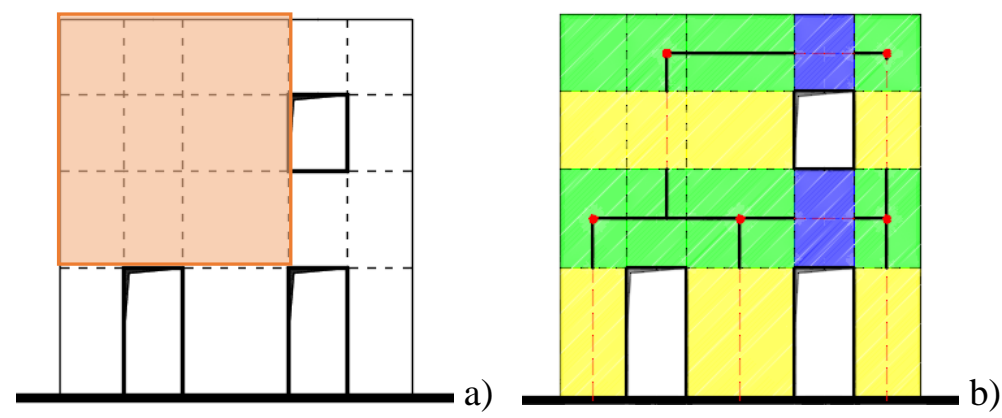

Figure 24: Example of wall with irregularity in number of openings (a) and corresponding EFM model (b).

With the aim to investigate the modelling issues related to the presence of irregularity in the number of openings, the two schemes of two-storey irregular walls shown in Figure 25 were studied. An irregularity index (Eq. 10) equal to 0.50 characterizes both the models, while the presence of the irregularity is located alternatively at both the levels of the wall. An effort to provide more effective EFM models were made for both the geometries. Using as reference the stress flows provided by the FEM models, new static scheme were defined trying to fit the system of internal forces transmission represented by the iso-static lines. The updated proposals follow also the prescription of the IBC [8] regarding the modelling criteria to adopt for existing masonry walls. IBC recommends, in fact, to assume as vertical resisting element of the ideal frame configuration such portion of the wall that maintains constant geometrical properties along its height. Figure 25 shows both the conventional and the proposed updated scheme for EFM modelling. Two piers with the same width along the height substitute, in the updated proposal, the macro-pier of the conventional EFM procedures. To guarantee the tension flow, a system of deep-beams connecting the two piers is included.
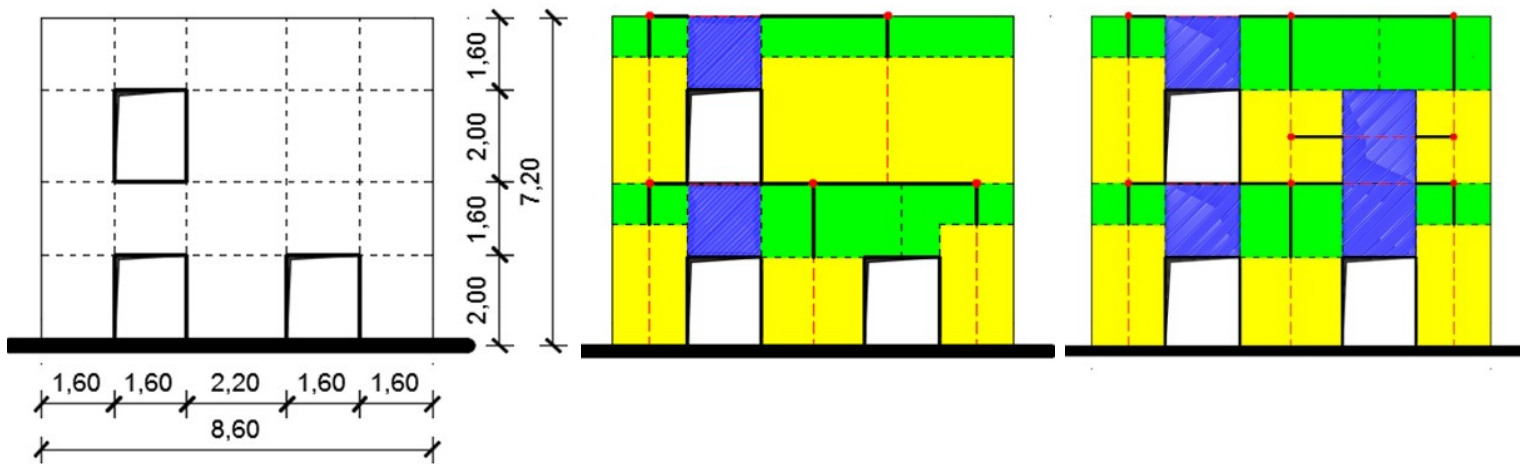

a)
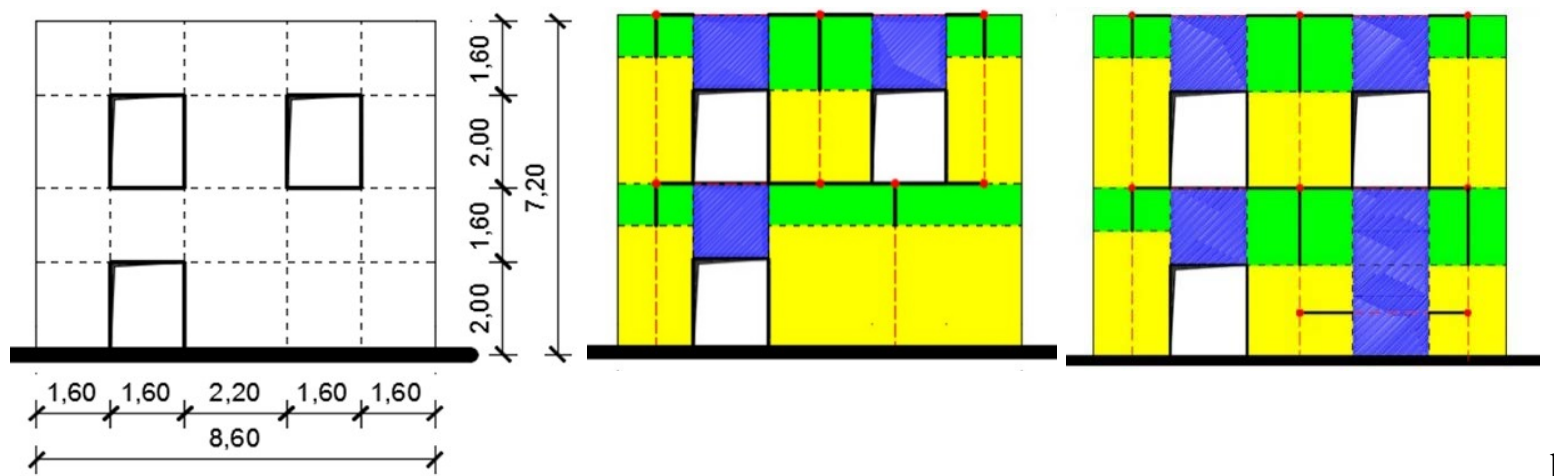

b)

Figure 25: Geometry of the tested walls with irregularity in number of openings at $1^{\text {st }}(a)$ and $2^{\text {nd }}(b)$ storey and corresponding EFM models (conventional scheme vs. proposed one).

By using the same criterion adopted for other types of irregularity, the accuracy of the updated schemes was estimated by comparing their results with those provided by FEM models in terms of base shear and horizontal displacements. The comparative study of EFM and FEM linear models shows an improvement of the EFM modelling accuracy for the updated proposals in both the tested 
geometries. The updated EFM models provide closer results to the FEM simulation than the conventional EFM configurations. The proposed models show good performance in particular in the simulation of the global stiffness of the wall, since almost negligible differences were observed in the prediction of the horizontal displacements compared to FEM. With reference to the case of irregularity at the $2^{\text {nd }}$ level (Figure 25a), Figure 26 shows the comparison between the horizontal displacements provided by the FEM model and the corresponding EFM ones defined according the conventional and the proposed schemes. The same comparison is presented in Figure 27 with reference to the case of irregularity at the $1^{\text {st }}$ level (Figure $25 \mathrm{~b}$ ). In both the cases, the proposed EFM schemes predict the horizontal displacement with negligible error compared to the FEM predictions. Differences ranging from $8 \%$ to $17 \%$ characterize the numerical predictions provided by the conventional EFM schemes with respect to the corresponding FEM models. A good agreement can be observed also in the prediction of the distribution of the base shear in the piers between the EFM updated model and the FEM, not reported hereafter for the sake of brevity.
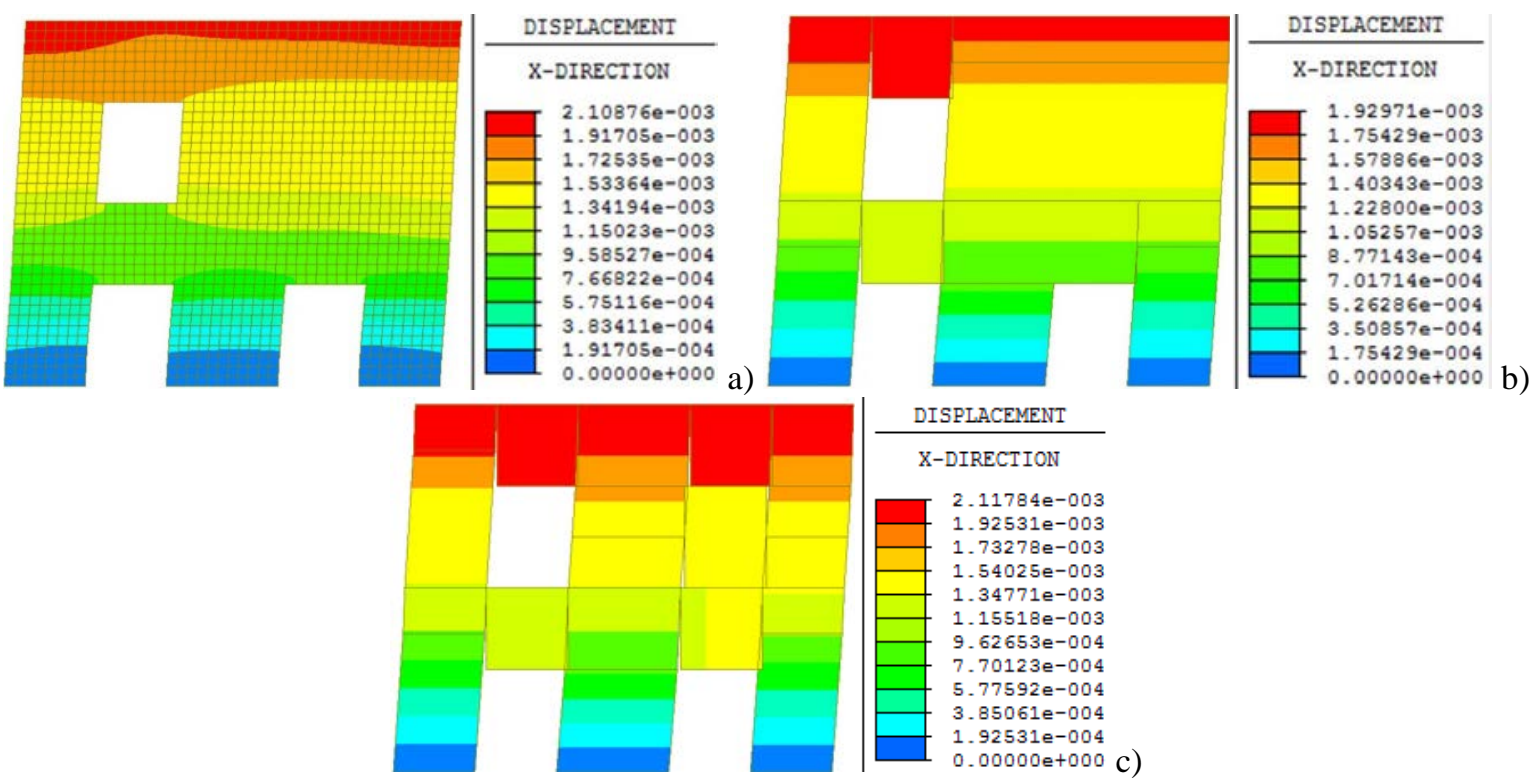

Figure 26: Comparison of horizontal displacements provided by the FEM (a) and the EFM models (conventional scheme (b) and proposed one (c) for the wall with irregularity in number of openings at $2^{\text {nd }}$ storey.
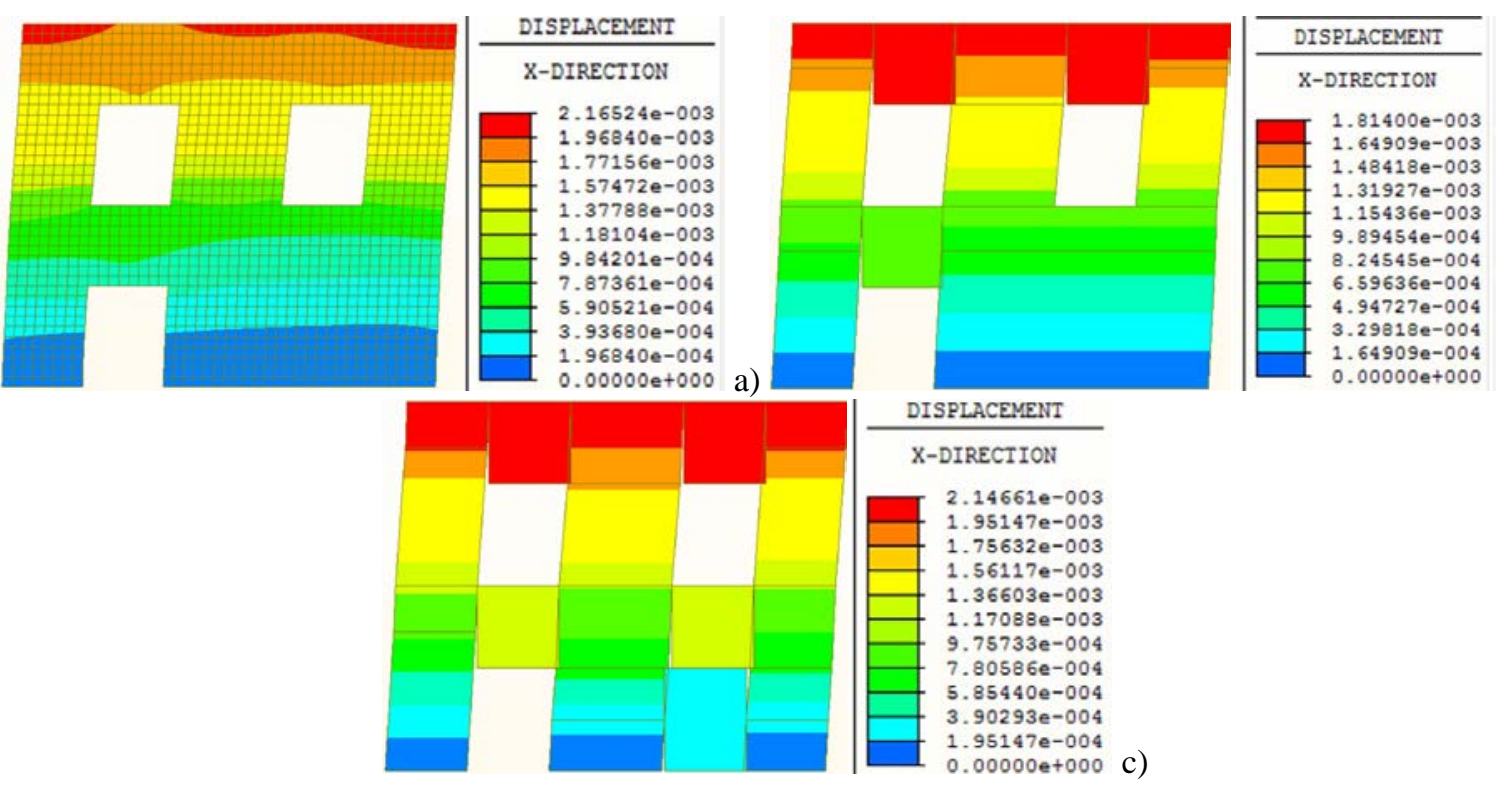

Figure 27: Comparison of horizontal displacements provided by the FEM (a) and the EFM models (conventional scheme (b) and proposed one (c) for the wall with irregularity in number of openings at $1^{\text {st }}$ storey. 


\section{FRAME-LIKE AND NON-FRAME-LIKE URM WALLS}

The distinction between regular and irregular walls [36] is essentially dependent on their geometrical configurations. The accuracy of the EFM in simulating the structural behaviour of regular and irregular configurations has been investigated in this research by finding a dependency of the numerical results on the geometrical properties of the URM walls.

The distinction between frame-like and non-frame-like configurations was introduced in Siano [15]. This different concept is strictly connected to the main theoretical basis of EFM, i.e. the approximation of a masonry wall to a plane frame. The definition of frame-like considers the geometrical affinity between an URM wall and a frame configuration.

The proposal of the distinction between frame-like and non-frame-like configurations, mainly related to the modelling strategy, added to the distinction between regular and irregular walls, mainly related to their geometry, leads to the identification of four major categories of walls, as shown in Figure 28. Independently from the regularity of the wall, the geometrical properties of piers and spandrels can make the wall adequate or not to be represented by a plane frame, i.e. frame-like or non-frame-like. In fact, the applicability of EFM should be carefully evaluated for the structural configurations far from frame-like requisites.

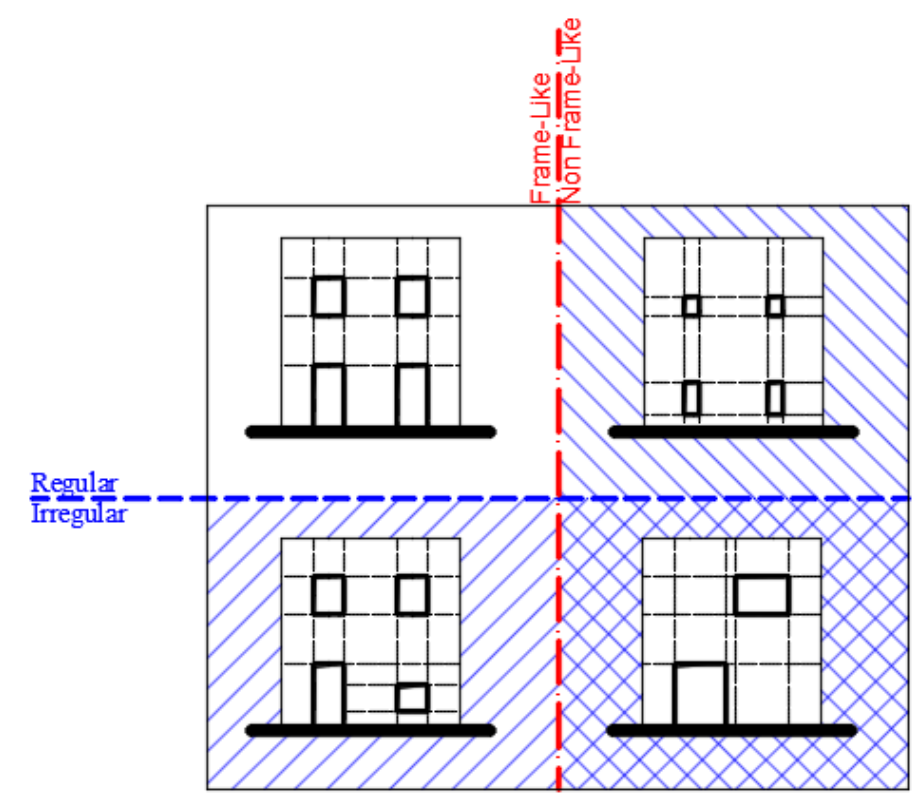

Figure 28: Classification of URM walls configurations according to geometrical and modelling criteria.

The quantification of the limits for each category has been one of the objectives of the present work. Representative parameters have been proposed to measure the degree of affinity of regular walls with a frame configuration. The same procedure has been followed for irregular walls by using the non-dimensional parameters found in the literature [17]. In both the cases, the accuracy of the numerical results obtained with EFM has been measured in terms of percentage differences with respect to the FEM results.

Focusing on the results obtained for regular walls (section 3.2), the parameters $\rho_{I}$ and $\rho_{S}$ have demonstrated to be adequate indicators of the consistency between the real masonry wall and its plane frame configuration. An increase of both parameters corresponds to a geometry less consistent with a frame configuration and thus the differences between EFM and FEM results tend to increase. This means that the parameters provided in this research can help to make a distinction between framelike and non-frame-like configurations. More specifically, it is possible to identify limit values for the parameters $\rho_{I}$ and $\rho_{S}$ corresponding to a defined scatter between EFM and FEM predictions. As already observed in section 3.2, a difference greater than $15 \%$ is obtained between EFM and FEM 
results for regular configurations having a stiffness ratio $\rho_{I}$ greater than 10 . In the case of the parameter $\rho_{S}$, the same difference between EFM and FEM results is obtained for regular walls having a slenderness ratio $\rho_{S}$ greater than 2 . These observation lead to the definition of specific limits for the EFM approach as a function of the two non-dimensional parameter introduced in this work.

Analogous considerations can be made for the irregular configurations of URM walls by paying attention to the different categories of irregularity. For these schemes, possible limits can be provided by assuming as a reference the irregularity indexes provided in Parisi and Augenti [17]. Critical results can be obtained for schemes affected by a horizontal irregularity index (eq. 6) greater than 0.20 when the irregularity is located at the base of the wall. For these schemes, percentage differences between EFM and FEM results have been obtained by the parametric analyses presented in this study.

\section{RECOMMENDATIONS FOR EFM}

The results presented in this study allow eventually the derivation of some recommendations for the improvement of the EFM accuracy. The objective is to preserve the simplicity of the application of EFM and, at the same time, to guarantee an acceptable level of effectiveness, comparable with that of more refined modelling methods.

Looking to the trends shown by the EFM models for regular and irregular walls, a different performance characterizes the two criteria proposed by Dolce and Augenti for the definition of the piers' effective height. The results show different capabilities to predict the forces and the displacements. Confirming the theoretical approaches that inspired each assumption, the models defined according to Dolce's criterion [3] demonstrate a greater accuracy in the simulation of the wall's deformability. On the other hand, the EFM models defined according to Augenti's criterion [17] provide lower errors in the prediction of the effective distribution of forces among the wall's structural components. This result confirms the importance of the geometrical calibration of the EFM models, but at the same time it indicates that the choice of the best modelling criterion depends on the sought information from the EFM analysis.

The non-dimensional parameters proposed in this study have provided another important tool for the evaluation of the EFM accuracy. Both in the cases of regular and irregular URM walls, these parameters represent indicators of the consistency between the wall geometry and the ideal frame configuration. They are function of the mutual geometrical relations between the main structural components of the wall, i.e. piers and spandrels. For this reason, it is possible, once fixed an acceptable error for the EFM predictions, to define the limits for the EFM approach expressed in terms of limit values of the proposed parameters. The definition of these parameters as a function of the wall's geometrical properties makes them a useful tool for professional practise.

Moving to the study of irregular URM walls, the analyses carried out allow to identify the greatest criticalities in the application of the EFM to irregular configurations. The results obtained underline the centrality of pier's geometry in altering the modelling results and consequently in limiting the effectiveness of the EFM. The geometrical dimensions of piers in the EFM models are the main element affecting the modelling accuracy and they need a careful calibration to improve their capability to describe URM walls performances. All the analyses carried out demonstrate that the types of irregularity that largely affect the accuracy of the results are those in which the changing dimension is the height of the piers, i.e. horizontal irregularity and offset irregularity in the horizontal direction.

Finally, the validation strategy proposed in this research can be generally used to improve the modelling accuracy of EFM also in critical cases characterized by more complex geometries and irregularities. As shown in section 4.3.3, the study of the results provided by FEM models, such as the stresses flows and the stiffness of each structural component, can provide useful information for the optimum calibration of the EFM models. Both in the case of regular and irregular configurations, 
FEM results can help in the identification of the most effective geometry to assign to piers or in the definition of an alternative equivalent scheme able to overcome the uncertainties in the simulation of the irregularities.

\section{CONCLUSIONS}

The present work has contributed to the evaluation of the validity and the limitations affecting the EFM in the simulation of the structural behaviour of URM walls. The delimitation of ranges of applicability for EFM is a necessary prerequisite to extend the validity of EFM also to existing masonry buildings, whose geometrical configurations can be incompatible with the theoretical hypotheses of EFM.

A comparative study has been presented between the results provided by EFM and FEM, by testing a wide range of sample walls characterized by geometrical configurations with a progressively increasing complexity. The validation procedure has involved linear models characterized by both regular and irregular geometrical configurations. For both these configurations, the modelling effectiveness of EFM has been interpreted by introducing the concept of frame-like to distinguish the walls that present or not a geometrical compatibility with an ideal frame configuration. A quantification of the concept of frame-like has been one of the main outcomes of the present work. With this aim, specific limit parameters have allowed the delimitation of the wall configurations that comply the requisite of frame-like, as a function of the geometrical properties of their panels.

In the case of regular walls, a wide parametric analysis has allowed to identify the geometrical configurations for which EFM proves to be no more suitable in structural modelling. The definition of proper non-dimensional parameters has given the possibility to interpret the modelling accuracy of EFM as a function of the walls' geometrical properties.

Regarding irregular geometrical configurations, non-dimensional indexes found in literature [17] have allowed the evaluation of the EFM modelling accuracy as a function of the amount of the irregularities. The reliability of EFM has been tested on a large series of selected critical cases reproducing four typologies of irregularity.

This study has allowed the definition of clear limits for the EFM adequacy and applicability for both regular and irregular walls. The sensitivity analyses carried out has shown an increase of the differences between EFM and FEM predictions for increasing geometrical complexity and amount of irregularity. Once fixed an acceptable limit for these differences, clear limits of the parameters have been identified for the application of EFM.

The results obtained provide a general overview of the modelling uncertainties affecting URM walls. They also represent a track to calibrate updated EFM models for walls characterized by strong geometric irregularities. In this way, it could be possible to improve the reliability of this modelling approach by preserving its simplicity of application and interpretation.

The analyses carried out demonstrate the centrality of a careful geometrical calibration of the resisting components of the EFM configuration, namely piers and spandrels. Therefore, starting from the observations provided here, ad hoc modelling solutions have been presented with satisfactory accuracy at least for regular and irregular walls that can be included into the set of frame-like configurations.

\section{ACKNOWLEDGEMENTS}

CSP Fea is deeply acknowledged for providing the software MIDAS Gen ${ }^{\circledR}$ [44] used in this work for the implementation of the numerical models. 
The financial support of University "G. D'Annunzio" of Chieti-Pescara is acknowledged by the authors. Partial support by the ReLUIS program 2014-2016 is also acknowledged by the authors.

\section{REFERENCES}

[1] Roca P, Cervera M, Gariup G, Pelà L. Structural analysis of masonry historical constructions. Classical and advanced approaches. Archives of Computational Methods in Engineering 2010; 17, 299-325.

[2] Roca P, Molins C, Mari AR. Strength capacity of masonry wall structures by the equivalent frame method. Journal Structural Engineering - ASCE 2005; 131(10):1601-1610. DOI: 10.1061/(ASCE) 0733-9445.

[3] Dolce M. Schematizzazione e modellazione degli edifici in muratura soggetti ad azioni sismiche. L’industria delle Costruzioni 1991; 25: $44-57$ [in Italian].

[4] Augenti N. Il calcolo sismico degli edifici in muratura. UTET Libreria. Torino, Italy, 2004 [in Italian].

[5] Brencich A, Gambarotta L, Lagomarsino S. A macro-element approach to the three-dimensional seismic analysis of masonry buildings. In: Proc. $11^{\text {th }}$ European Conference on Earthquake Engineering. Paris, France, 1998.

[6] Galasco A, Lagomarsino S, Penna A, Resemini S. Non-linear seismic analysis of masonry structures. In: Proc. $13^{\text {th }}$ World Conference on Earthquake Engineering. Vancouver, Canada, 2004; paper n. 843.

[7] Calderini C, Cattari S, Lagomarsino S. In plane seismic response of unreinforced masonry walls: comparison between detailed and equivalent frame models. In: COMPDYN 2009 - ECCOMAS Thematic Conference on Computational Methods in Structural Dynamics and Earthquake Engineering. Rhodes, Greece, 2009.

[8] Magenes G, Penna A, Senaldi I, Rota M, Galasco A. Shaking table test of a strengthened full scale stone masonry building with flexible diaphragms. International Journal of Architectural Heritage 2014; 8(3): 349-375.

[9] Penna A, Senaldi I, Galasco A, Magenes G. Numerical Simulation Of Shaking Table Tests On Full-Scale Stone Masonry Buildings. International Journal of Architectural Heritage 2015, DOI: 10.1080/15583058.2015.1113338.

[10] Cattari S, Giongo L, Marino S, Lin Y, Schiro G, Ingham JM, Dizhur D. Numerical simulation of the seismic response of an earthquake damaged URM building. In: New Zealand Society for Earthquake Engineering Technical Conference 2015 Conference. 2015.

[11] Calvi GM, Magenes G. Experimental research on response of URM building systems. In: Proc. U.S. Italian Workshop on Guidelines for Seismic Evaluation and Rehabilitation of Unreinforced Masonry Buildings. 1994.

[12] Marques R, Lourenço PB. Possibilities and comparison of structural component models for the seismic assessment of modern unreinforced masonry buildings. Computers and Structures 2011; 89: 2079-2091.

[13] Marques R, Lourenço PB. Unreinforced and confined masonry buildings in seismic regions: validation of macro-element models and cost analysis. Engineering Structures 2014; 64: 52-67.

[14] Pantò B, Raka E, Cannizzaro F, Camata G, Caddemi S, Spacone E, Caliò I. Numerical macro-modelling of unreinforced masonry structures: A critical Appraisal. In: Proc. $15^{\text {th }}$ International Conference on Civil, Structural and Environmental Engineering Computing, 2015.

[15] Siano R. On the equivalent-frame method for irregular masonry walls. PhD Dissertation, University "G. d'Annunzio" of Chieti-Pescara. Pescara, Italy, 2016.

[16] Siano R, Camata G, Sepe V, Spacone E, Roca P, Pelà L. Numerical validation of Equivalent-Frame models for URM walls. IN: Proc. VII European Congress on Computational Methods in Applied Sciences and Engineering - ECCOMAS 2016; Crete Island, Greece.

[17] Parisi F, Augenti N. Seismic capacity of irregular unreinforced masonry walls with opening. Earthquake Engineering \& Structural Dynamics 2013; 42: 101-121.

[18] Italian Building Code. D.M. 14/01/2008: Norme Tecniche per le Costruzioni. Italian Ministry of Infrastructures and Transportation. G.U. S.O. n. 30 on 04/02/2008 [in Italian]. 
[19] EN 1998-1. Eurocode 8. Design of Structures for earthquake resistance - Part 1: General rules, seismic actions and rules for buildings. CEN, Brussels, Belgium, 2004.

[20] EN 1998-3. Eurocode 8, Design of structures for earthquake resistance - Part 3: Assessment and retrofitting of buildings. CEN, Brussels, Belgium; 2005.

[21] Pelà L, Benedetti A, Aprile A, Mangoni E. Seismic Assessment of the Milano Centrale Railway Station. International Journal of Architectural Heritage 2013; 7:609-627.

[22] Page AW. Finite element model for masonry. Journal of Structural Div. ASCE 1978; 104(8): 1267-1285.

[23] Cundall PA. Formulation of a three-dimensional distinct element model - Part I: A scheme to detect and represent contacts in a system composed of many polyhedral blocks. International Journal of Rock Mechanics and Mining Sciences \& Geomechanics Abstracts 1988; 25(3):107-116.

[24] Hart RD, Cundall PA, Lemos J. Formulation of a three-dimensional distinct element model - Part II: Mechanical calculations for motion and interaction of a system composed of many polyhedral blocks. International Journal of Rock Mechanics and Mining Sciences \& Geomechanics Abstracts 1988; 25(3):117-125.

[25] Applied Technology Council (ATC). FEMA 440 - Improvement of nonlinear static seismic analysis procedures. Redwood City, California, U.S.A, 2005.

[26] Tomaževič M. The Computer Program POR, Report ZRMK, Institute for Testing and Research in Materials and Structures, Ljubljana, Slovenia; 1978 [in Slovenian].

[27] Magenes G, Della Fontana A. Simplified Non-linear Seismic Analysis of Masonry Buildings. In: Proc. of the British Masonry Society; 1998(8): 190-195.

[28] Lagomarsino S, Penna A, Galasco A, Cattari S. TREMURI program: an equivalent frame model for the nonlinear seismic analysis of masonry buildings. Engineering Structures 2013; 56:1787-1799.

[29] Caliò I, Marletta M, Pantò B. A simplified model for the evaluation of the seismic behaviour of masonry buildings. In: Proc. $10^{\text {th }}$ International Conference on Civil, Structural and Environmental Engineering Computing 2005; Rome, Italy, Paper nº 195.

[30] 3DMacro. http://www.murature.com/3DMacro/download.php [8 September 2014]

[31] Casolo S, Peña F. Rigid element model for in-plane dynamics of masonry walls considering hysteretic behaviour and damage. Earthquake Engineering and Structural Dynamics 2007; 36(8): 1029-1048.

[32] Magenes G, Calvi GM. In-plane seismic response of brick masonry walls. Earthquake Engineering and Structural Dynamics 1997; 26(11):1091-1112.

[33] Turnšek V, Čačovič F. Some experimental results on the strength of brick masonry walls. In: Proc. of the $2^{\text {nd }}$ International Brick \& Block Masonry Conference, Stoke-on-Trent, United Kingdom, 1970; 149-156.

[34] Tomaževič M. Masonry Structures in Seismic Areas - A state of art Report. In: Proc. 9 th $^{\text {European }}$ Conference on Earthquake Engineering 1990; Moscow, Russia, vol. A: 247-302.

[35] Applied Technology Council (ATC). FEMA 356 - Pre-standard and commentary for the seismic rehabilitation of buildings. Washington DC, U.S.A, 2000.

[36] Augenti N. Seismic behaviour of irregular masonry walls. In: Proc. $1^{\text {st }}$ European Conference on Earthquake Engineering and Seismology. Geneva, 2006; paper n. 86.

[37] Paquette J, Bruneau M. Pseudo-dynamic testing of unreinforced masonry building with flexible diaphragm. Journal of Structural Engineering 2003; 129(6): 708-716.

[38] Yi T, Moon FL, Leon RT, Kahn LF. Lateral load tests on a two story unreinforced masonry building. Journal of Structural Engineering - ASCE 2006; 132(5): 643-652.

[39] Berto L, Saetta A, Scotta R, Vitaliani R. An orthotropic damage model for masonry structures. International Journal for Numerical Methods in Engineering 2002; 55: 127-157.

[40] Gambarotta L, Lagomarsino S. Damage models for the seismic response of brick masonry shear walls. Part I: The mortar joint model and its applications. Earthquake Engineering and Structural Dynamics 1997, 26: 441-462.

[41] Gambarotta L, Lagomarsino S. Damage models for the seismic response of brick masonry shear walls. 
Part II: The continuum model and its applications. Earthquake Engineering and Structural Dynamics 1997, 26: 441-462.

[42] Pelà L, Cervera M, Roca P. An orthotropic damage model for the analysis of masonry structures. Construction and Building Materials 2013, 41:957-967.

[43] Petracca M, Pelà L, Rossi R, Oller S, Camata G, Spacone E. Regularization of first order computational homogenization for multiscale analysis of masonry structures. Computational Mechanics 2016, 57:257276. DOI: 10.1007/s00466-015-1230-6.

[44] MIDAS Gen (C), MIDAS Information Technology Co. 